\title{
EL PRINCIPIO DE INEXCUSABILIDAD Y EL DERECHO DE ACCIÓN DESDE LA PERSPECTIVA DEL ESTADO CONSTITUCIONAL*
}

\author{
THE PRINCIPLE OF INEXCUSABILITY AND THE RULE OF ACTION \\ FROM THE CONSTITUTIONAL POINT OF VIEW
}

\section{Patricio Martínez BenaVides**}

\begin{abstract}
RESUMEN: Se pretende realizar una reflexión acerca del principio constitucional de la inexcusabilidad desde un punto de vista procesal civil, en cuanto correlato orgánico y contracara del derecho de acción, en su actual comprensión como derecho fundamental a la tutela jurisdiccional efectiva. Para ello, se realizará una breve noticia de su alcance, para luego plantear una ampliación de su comprensión a la luz del paradigma del Estado Constitucional.
\end{abstract}

Palabras dave I nexcusabilidad, non liquet, derecho de acción, acceso a la justicia, derecho fundamental a la tutela efectiva de los derechos.

ABSTRACT: We intend to make a reflection on the constitutional principle of inexcusability from a civil procedural standpoint, as an organic correlate and counter face to the right to be heard in its current understanding as fundamental right to the effective judicial protection. For this, we will make a brief account of its scope, and then we will propose an extension of its meaning in the light of the constitutional state paradigm.

Key words $N$ on liquet, rule of action, right to be heard, fundamental right to effective jurisdictional guardianship.

\section{INTRODUCCIÓN}

El presente trabajo tiene por fin proponer una reformulación del principio de inexcusabilidad, a la luz de las exigencias del paradigma del Estado C onstitucional.

Tradicionalmente, como se pretenderá demostrar a lo largo de estas líneas, el principio de inexcusabilidad ha sido comprendido con un alcance limitado al mero deber de faIlar que le corresponde al órgano judicial, y este a su vez, restringido a la comprensión de la prohibición del non liquet, en cuanto regla que alcanza relevancia frente a la situación -improbable- de ausencia concreta de ley decisoria litis, por lo que se ha considerado tal

\footnotetext{
* Trabajo realizado dentro del proyecto regular Fondecyt $N^{\circ}$ 1111021-2011, "Principios de la tutela ejecutiva del crédito", siendo su investigador principal, el D r. Álvaro Pérez-Ragone.

** Profesor en la Facultad de Ciencias Jurídicas de la Universidad de Atacama. Licenciado en D erecho, Pontificia Universidad C atólica de Chile, Alumno del Programa de D octorado en D erecho de la Pontificia U niversidad Católica de Valparaíso, Juez Titular del Cuarto Juzgado de Letras de Copiapó. Correo electrónico: pmartinezb@gmail.com.
} 
principio como una prohibición de justificación del no ejercicio de jurisdicción en dicho caso, que impide eludir la resolución de los negocios puestos bajo su conocimiento, desplegada como cláusula excepcional que autoriza la integración, como fuente de derecho, en el caso de ausencia de ley, de la jurisdicción de equidad.

Sin embargo, creemos que con la influencia de lo que se puede denominar el paradigma del Estado Constitucional, dicho alcance restringido que tradicionalmente se le ha asignado, pierde relevancia, de modo que se hace necesaria una reformulación del mismo. En efecto, en dicho sentido, sostenemos que el principio de inexcusabilidad, puede servir de sustento o base de la formulación del derecho de acción, entendido como derecho fundamental de acceso a la justicia y de tutela efectiva de los derechos.

Para lo anterior, se intentará en primer lugar, una breve noticia sobre algunos aspectos del origen del principio inexcusabilidad en su proceso de positivación en Chile, para describir el alcance que la visión tradicional del principio de la inexcusabilidad le ha entregado, para luego, a partir del concepto de Estado Constitucional, considerar el principio desde una dimensión fundada en la perspectiva de los derechos fundamentales, a fin de desplegarlo como fundamento, principio y mandato de optimización, e incluso, como contracara orgánica del derecho de acción procesal, en la comprensión antes aludida, y finalmente tratar brevemente los efectos de dicha propuesta de configuración del principio materia de estudio.

\section{EL ESTATUTO TRADICIONAL DEL PRINCIPIO DE INEXCUSABILIDAD}

\subsection{El surgimiento del principio: El Estado Liberal Legislativo}

El principio de la inexcusabilidad se ha relacionado históricamente con la vinculación del juez a la ley, donde la referida regla corresponde a la opción estatal que consagra el deber de fallar por parte del juez, como obligación inexcusable, incluso en el caso de enfrentamiento a una laguna legal, excluyendo de este modo la posibilidad de declaración de non liquet o de sin solución de algún asunto puesto en conocimiento del judicial.

En nuestro país existe una norma que desde el año 1875 recoge de manera expresa la opción de la inexcusabilidad, la que se mantiene inalterable hasta el día de hoy y además consagrada, a nivel constitucional, cuyo fundamento, según algunos autores ${ }^{1}$, se encontraría en el derecho hispánico.

Sin embargo, creemos que el perfil tradicional del principio de inexcusabilidad, se gesta en el modelo jurídico que vino a reemplazar el paradigma del derecho indiano y castellano, esto es, el modelo político del liberalismo ilustrado francés, que al contemplar como base el principio de la Supremacía de la Ley, redujo la comprensión y la expectativa del concepto de la labor judicial, al de simple aplicador de la ley, constituyéndose no solo en el tercer poder, sino en el último poder del Estado², poder de cualquier modo, nulo3, por cuanto el legislador, motivado por la ideología del Estado Liberal de D erecho, quería

\footnotetext{
${ }^{1}$ Topasio (I983) y Figueroa (1996). También se hace tal referencia en obras generales de historia del derecho, por todos, ver Eyzaguirre (2003).

2 Bravo (2009) p. 195.

${ }^{3}$ Montesquieu, D e l'esprit des lois, cit. por Tarello (1987) p. 291.
} 
evitar a cualquier costo, que los jueces pudiesen pervertir la voluntad democrática del pueblo, concretada en el órgano legislativo.

Este contexto justifica el uso del recurso del "non liquet" o de la declaración de "no líquido" de un asunto judicial, regla por la cual, el juez debía declarar una cuestión sin solución, especialmente en el caso de enfrentarse a una situación concreta no regulada por la ley. 0 más específicamente el denominado referé legislatif, o cláusulas de remisión al legislador, para que este aclare, interprete o subsane la falta u oscuridad de la ley.

Sin embargo en Francia, y también en Chile, la opción definitiva que enmarcaría la actividad judicial, no fue la del referimiento al legislador, sino una fórmula que obliga al juez a realizar su labor a todo evento, tal como lo encontramos en el Code Civil francés, en su título preliminar, específicamente en su artículo $4^{\circ}$ : "El juez que rehúse juzgar, bajo pretexto de silencio, oscuridad o insuficiencia de la ley, podrá ser perseguido como culpable de denegación de justicia" ${ }^{4}$, que se justifica, por un lado, por el abuso práctico en que incurrieron los jueces bajo la obligación de referir el caso sin solución; por otro lado, hay una justificación dogmática, consistente en la visión crítica y además antiingenua, de la pretensión positivista de la completitud e integridad del sistema jurídico5, pero principalmente, creemos que intercede en esta decisión, un elemento de carácter político e ideológico, donde al Estado le pareció más coherente y efectivo, desde el punto de vista de los poderes del Estado, tolerar cierta licencia al juez en su vínculo con la ley, con el fin de favorecer la consagración de un deber estatal de realizar la actividad judicial a todo evento y de manera inexcusable.

En efecto, si la función judicial se comprende principalmente a la luz de los principios del liberalismo clásico del Estado Legislativo, fundado, por ejemplo, en la ficción de la igualdad de los ciudadanos, su objetivo primordial, sería la resolución de conflictos que surgen entre los ciudadanos privados, por lo que una la declaración de non liquet, implicaría el incumplimiento de uno de los fundamentos filosóficos que lo sustentan, pues "restaurar y proteger, en todo momento, el orden y la paz social"7, es uno de los fines constitutivos "de la función primaria del derecho y del Estado"8.

De modo que si el objeto de la labor judicial es otorgar paz social y especialmente seguridad jurídica9 - valor que se alza como cardinal en el Estado Liberal de Derecho-, el juez no puede excusarse de resolver los conflictos que se le proponen, sin desperfilar gravemente la estructura política estatal.

El artículo $4^{\circ}$ del Código Civil francés, recoge este principio liberal, comprendiendo la labor judicial -específicamente el "juzgar"-, como deber siempre ineludible, incluso

\footnotetext{
4 Traducción obtenida en www.legifrance.gouv.fr, donde la norma en francés es: "Le juge qui refusera de juger, sous prétexte du silence, de l'obscurité ou de l'insuffisance de la loi, pourra éter poursuivi comme culpable de déni de justice" [visitado por última vez el 31 de marzo de 2011].

${ }^{5}$ Montoro (1980) p. 82.

6 Para Marinoni et al. (2010), este sería un punto de quiebre en el paradigma del Estado Legislativo, pues: "Si hay normas que violan los principios de justicia y los derechos fundamentales, existen omisiones, o ausencia de normas, que agreden esos mismos" p. 58.

${ }^{7}$ Montoro (1980) p. 86.

${ }^{8}$ Montoro (1980) p. 86.

9 Ver Calamandrei (1960) p. 257.
} 
Martínez Benavides, Patricio “ "El principio de inexcusabilidad y el derecho de acción..."

en el caso más grave para este paradigma presidido por la supremacía legal: el silencio, oscuridad o insuficiencia de la ley.

Además, en este último caso, se autorizaba al juez, de manera excepcional, a recurrir a una fuente diversa a la ley, con el objeto de subsanar el defecto legal, esto es, por medio de la equidad, tal como lo propone PorTALis ${ }^{10}$ al referirse a ella como herramienta de integración de la laguna legal. Si bien dicha solución fue ampliamente debatida en la aprobación del Code Civil ${ }^{11}$, finalmente se aceptó en razón de la necesidad indispensable de establecer este deber judicial, frente a la mala experiencia del sistema del réferé legislatif.

\subsection{La positivaCión del principio de la ineXCusabilidad en Chile}

Nuestro país, en los albores de la República, se caracterizó por la fuerte influencia francesa que imprimió a sus instituciones, donde fue especialmente notorio el influjo del Código Civil francés. En efecto, el redactor de nuestro Código Civil, efectuó dos propuestas en el proyecto de 1853, donde intentó consagrar el referido principio -la última de ellas, de redacción casi idéntica al mencionado artículo del Código francés-, pero que posteriormente fueron excluidas del proyecto definitivo, por considerar la comisión revisora, que dicha norma era propia de un código de procedimiento ${ }^{12}$.

Sin embargo, no fue en la legislación propiamente procedimental en la que se recogió expresamente la inexcusabilidad, pues ella se verificó por primera vez a través del inciso segundo del artículo $9^{\circ}$ de la Ley de 0 rganización y Atribuciones de los Tribunales del año 1875: "Reclamada su intervención en forma legal i en negocios de su competencia, no podrán escusarse de ejercer su autoridad ni aún por falta de lei que resuelva la contienda sometida a su decisión"13, en una clara referencia al artículo $4^{\circ}$ del Código Civil francés, como lo reconoce BaLLESTERos ${ }^{14}$.

Dicho principio fue consagrado posteriormente, en el actual artículo 76 de nuestra CPR, específicamente en su inciso segundo: "Reclamada su intervención en forma legal y en negocios de su competencia, no podrán excusarse de ejercer su autoridad, ni aun por falta de ley que resuelva la contienda o asunto sometidos a su decisión", lo que elevó el principio de inexcusabilidad, a rango constitucional, con una mínima variación en su redacción, por cuanto, mientras el texto legal señala "la contienda sometida a su decisión", el texto constitucional agrega la frase "contienda o asunto", ampliando su ámbito de aplicación.

\subsection{AlCANCE DEL PRINCIPIO DE INEXCUSABILIDAD}

Este despliegue normativo, y la comprensión francesa del principio, redundó en que el alcance de la inexcusabilidad, se dirija en dos sentidos, por un lado, como una mera prohibición para el juez de apartarse de cumplir su deber de fallar, y por otro, como una

\footnotetext{
10 Portalis (1959) p. 42.

11 Para una noticia de este asunto, ver Husson (1980).

12 GuZMán (2007) p. 45.

13 Ballesteros (1890) p. 127.

14 Ballesteros (1890) p. 130 (por error, impresa como 103): El autor luego aclara que el juez "no ejerce propiamente el poder legislativo, por que su sentencia no tiene jamás el efecto de una lei".
} 
cláusula excepcional, que autoriza la integración de la equidad como fuente del derecho, en el caso de defecto de ley.

Una revisión de las obras más conocidas de ambas ramas, aś lo confirman, por ejemplo Alejandro Silva Bascuñán en su Tratado, se refiere a la inexcusabilidad como la obligación de "los tribunales de pronunciarse cuando a ellos se recurre en forma legal"15, en caso de ausencia de norma, sostiene dicho autor, el juez debe salvar su carencia "ideando lo que convenga dentro de la aspiración de justicia que debe informar la vocación de la magistratura"; en el mismo sentido, Verdugo, Pfeffer y Nogueira, al identificar el principio de inexcusabilidad con el deber de fallarib. Lo mismo apreciamos en los autores de derecho procesal, donde tratado como principio, la inexcusabilidad se decanta en el deber de fallar ${ }^{17}$.

Creemos que la explicación más precisa a este sentido es aquella que describe la inexcusabilidad señalando que "significa en buenas cuentas, que la Jurisdicción no puede hacer nunca dejación de su cometido de declarar el derecho entra las partes mediante la emisión del juicio"18, que entendiendo la jurisdicción como una potestad, tanto el constituyente como el legislador, han prohibido el abandono de su ejercicio a todo evento.

M ás interesante nos parece, es la otra vertiente de comprensión del principio, en cuanto cláusula de autorización de creación de derecho por parte del juez, pues si bien, como hemos señalado, tanto en el derecho procesal como constitucional, la inexcusabilidad se ha comprendido tradicionalmente como sinónimo del deber de fallar, se trata en estricto rigor, de una prohibición que tiene como destinatario al órgano judicial, lo que se hace especialmente notorio en su consagración constitucional, ocasión en que se despliega claramente como mandato dirigido al Poder Judicial, en cuanto le impide excusarse de cumplir su función.

Incluso hay quienes extremando posiciones, han intentado diferenciar la inexcusabilidad del deber de fallar ${ }^{19}$, reduciendo su alcance al solo caso específico de la posibilidad de integración del derecho y aplicación de la jurisdicción de equidad en caso de laguna legal, identificándolo como una regla que autoriza a suplir el defecto de ley mediante la aplicación de "los principios de equidad" (artículo 170 N 05 del CPC), y de la "equidad natural" (artículo 24 del CC chileno) ${ }^{20 .}$

\subsection{La INEXCUSABILIDAD Y LA CUESTIÓN DEL JUEZ Y LA CREACIÓN DEL DERECHO}

En este punto, resulta interesante detenernos en la posibilidad de creación de derecho por parte del juez, que es a lo que eventualmente autorizaría la cláusula excepcional que contiene la inexcusabilidad frente a la ausencia de ley decisoria litis.

\footnotetext{
15 Silva (2010).

${ }^{16}$ Verdugo et al. (1994) p. 186: "Los tribunales deben resolver siempre los asuntos que siendo de su compe tencia se someten a su conocimiento, aun a falta de ley, situación esta en que para fallarlos deberán atenerse al espíritu general de la legislación y a la equidad natural".

17 Ver por ejemplo, Casarino (1995) p. 91, donde señala que la ley les ha impuesto a los jueces: "la obligación de ejercer su ministerio cada vez que son requeridos en la forma legal".

${ }^{18}$ C arocca (1997) p. 39.

${ }^{19}$ Ansaldi et al. (2008).

${ }^{20}$ Figueroa (1996) p. 189.
} 
Si bien no es materia de estas líneas, debemos resaltar la importancia de dicho asunto, pues recordemos que en la base del Estado Legislativo, se encuentra el principio de la supremacía de la ley, en cuanto producto de la voluntad soberana, que lleva a identificar el derecho con los contenidos de los cuerpos legales; de modo que en ese contexto, la posibilidad de vacío legal frente a un caso concreto, enfrenta al Estado a un problema de relevancia, ya que optar por algún sistema de requerimiento al legislador para reparar dicho defecto, significa desperfilar el caro principio de separación de funciones, y la eficacia de la nueva conformación estatal, además de los problemas prácticos que genera en el ejercicio de la función jurisdiccional. Por lo anterior, la regla general es la opción de aceptar la posibilidad -excepcional- de que el juez pudiese "crear" derecho frente a la laguna legal, de cara al rol del Estado Legislativo.

Por lo menos así lo cree posible Eugenio Bulygin, quien se manifiesta a favor de reconocer la posibilidad de creación de derecho por parte del juez, exactamente en el caso de defecto de ley, al señalar que los jueces crean normas generales, justamente "cuando se enfrentan con casos de lagunas o contradicciones normativas" 21 , entendiendo esta situación, como un caso excepcional en que el juez crea norma de carácter general.

Así también lo entiende ENDicotт, al identificar Estado Legislativo con el "imperio de la ley", señalando que en dicho paradigma, la función de los tribunales es también una "función creativa de resolver las disputas irresueltas sobre las exigencias del derecho", concluyendo que los jueces por lo tanto "tienen el deber de dar (de hecho, de imponer) una resolución. La resolución es una exigencia básica del imperio de la ley"22, que implica una labor de creación.

Lo anterior se opone principalmente, a la postura que niega la posibilidad de existencia de lagunas legales, o que asume, que aun cuando existiesen, siempre son solubles a partir del sistema legal vigente, contexto en que el recurso a la equidad sería inadmisible²3. En un sentido intermedio, se expresa TEJADA ${ }^{24}$, al señalar que en el sistema de la supremacía legal, la prohibición del non liquet, implica tolerar un margen de discrecionalidad judicial25, aunque no la acepta como creación de derecho.

A nuestro juicio, estas visiones son también responsables del encuadramiento restringido del alcance del principio de la inexcusabilidad, pues el alcance que se le ha dado al principio de la inexcusabilidad, es justamente verlo como norma de excepción, por el cual, en el caso concreto y estricto, de que el juez se enfrente a una laguna o defecto de ley, la Constitución ha tomado la opción de imponer al juzgador la obligación, y la posición de articular una norma que permita satisfacer el cumplimiento del deber jurisdiccional.

Lo anterior se encuentra íntimamente ligado, sin duda alguna, con la obligación de fundamentación de las resoluciones judiciales, pues en este caso concreto, es gravamen del juez motivar adecuadamente la circunstancia de la presencia de una laguna legal - sea au-

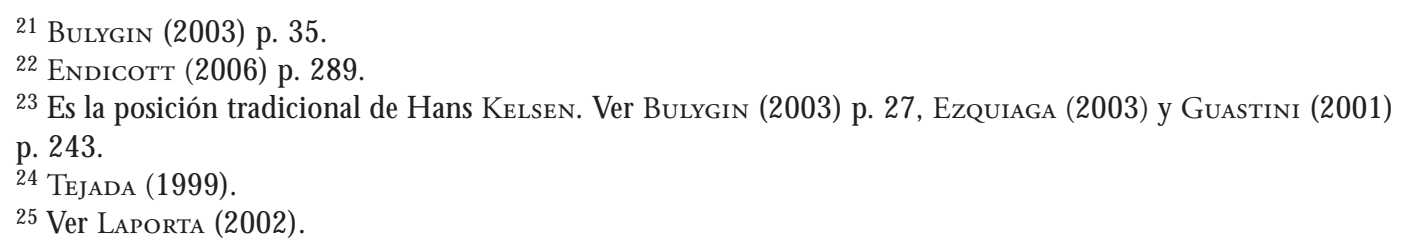


sencia, oscuridad o insuficiencia de la ley-, a fin de justificar debidamente la "creación de la norma" que satisfaga el cumplimiento del ejercicio de la jurisdicción.

Si bien es aceptado que el ejercicio de la jurisdicción incluye la obligación de motivación de la decisión, en cuanto elemento integrante de la garantía del debido proceso26, en el caso de la utilización de la equidad $u$ otra fuente ajena a la ley, se le exige al sentenciador una carga argumentativa anexa, pues antes de motivar la decisión de mérito del proceso, debe justificar el uso de la cláusula excepcional de la inexcusabilidad, que le permita fundar su decisión en una fuente no legal27, debiendo argumentar acerca del silencio, oscuridad, deficiencia o contradicción de la ley que lo lleva a esta labor.

De este modo, y resumiendo lo ya dicho, la inexcusabilidad corresponde a la particular situación de autorización excepcional que permite al juez alejarse del principio de legalidad.

En efecto, en dicho sentido, la inexcusabilidad se despliega como un principio procesal orgánico de una función jurisdiccional que se explica y agota en el deber de fallar, deber que a su vez se justifica, en la solución de conflictos de relevancia jurídica entre privados, reduciéndose su utilidad y relevancia al caso excepcional de falta de ley que resuelva el litigio, y que además su aplicación se limitaría de modo preferente a la jurisdicción civil y contenciosa.

Así, la inexcusabilidad, es el principio que concreta el ideal del Estado Legislativo respecto los deberes del poder judicial28, a saber: 1 . El deber de fallar, que incluye la prohibición del non liquet, 2 . El deber de atenerse siempre al sistema de fuentes, que en nuestro sistema continental, corresponde de modo preponderante, a la ley, y 3. El deber de motivar las sentencias, en cuanto justificación de la decisión a partir de razones fundadas en el sistema de fuentes 29 , de modo que la jurisdicción se configura, no solo como una facultad, sino al mismo tiempo como un poder-deber de resolución de controversias del ámbito privado.

Sin embargo, la tradición de la codificación, y su formalismo, olvida detalles importantes, que la tradición del common law no olvida, al añadir a los deberes antes señalados, otros de la misma importancia, como mantener "la integridad y decencia del proceso judicial (... ) la dirección y guía del jurado de modo justo (... ) y la determinación de los hechos en los juicios sin jurado"30, que dicen relación con elementos que no caben dentro del formalismo del Estado Legislativo.

Por ello creemos que el principio de inexcusabilidad implica una amplitud mayor que obliga a considerarlo como algo que va más allá de una prohibición, sino que exige

\footnotetext{
26 TARUfFo (2005) pp. 166-174.

27 TARuffo (2005) para quien la obligación de motivación de la sentencia, corresponde a una exigencia de carácter técnico que permite la impugnación de la misma, que en el contexto que nos situamos toma aún mayor relevancia: "(... ) la motivazione de la sentenza, intesa come requisito técnico del provvedimento giurisdizionale (... ) questa funzione é conessa directamente con l'impugnazione della sentenza".

${ }^{28}$ LAPORTA (2002).

${ }^{29}$ Guastini (2001).

30 Endicotт (2006) p. 221. D e este modo, el autor amplía las exigencias que el Estado le impone al judicial, ampliando el contenido del deber de fallar, comprendido como parte integrante -si es que los hay- de los derechos procesales.
} 
una acción del judicial, como el otorgar a las partes y operadores jurídicos, la prestación o garantía de los derechos procesales - si es que los hay-, y garantizar la "justicia" en el proceso, o por lo menos su "fair play". Sin embargo, en la práctica se ha mantenido su comprensión limitada a un grueso y aproblemático deber de fallar, que incluso ha reducido su importancia al caso específico y excepcional de apertura a la jurisdicción de equidad en caso de vacío legal, que además, como diremos, ha perdido relevancia frente al advenimiento del Estado Constitucional.

La consagración constitucional del principio de inexcusabilidad en la CPR del año 1980, no modificó mucho la comprensión restringida que se le ha otorgado, a pesar de la inclusión a la redacción del año 1875 que perdura en el vigente artículo 76 de la Carta Fundamental, de la palabra "asunto", además de "contienda", a fin de permitir una ampliación a su ámbito de aplicación (por lo menos así lo manifiesta el señor Bertelsen en la Comisión "O rtúzar", al explicar por qué no propuso la repetición textual del artículo 10 del (OT) ${ }^{31}$, pues su desarrollo doctrinal posterior lo ha mantenido igualmente enfocado como la regla de excepción, que autoriza la creación de norma general en el estricto caso de falta de ley, o por lo menos autoriza excepcionalmente la apertura de fuentes a la equidad 32 .

\section{EL PRINCIPIO DE INEXCUSABILIDAD EN ELTRÁNSITO DEL ESTADO LEGISLATIVO AL ESTADO CONSTITUCIONAL}

La sistematización que se le ha dado a la inexcusabilidad, según se ha señalado, lo ha estructurado como un principio general tanto del derecho constitucional como procesal, que correspondiente al deber de fallar que le atañe al judicial, incluye en su interior, como cláusula que complementa la prohibición, una regla excepcional al contexto histórico de su surgimiento, que autoriza la creación de derecho frente al estricto caso de falta de ley, abriendo el sistema de fuentes centrado en la ley y su supremacía, a la jurisdicción de la equidad, configurando un mandato-prohibición, dirigido a los órganos del Poder Judicial, que les impide apartarse del deber de fallar.

Como también se ha dicho, la estructura normativa o estatuto que consagra el principio de inexcusabilidad en nuestro país $5^{33}$, es genéticamente tributaria de las concepciones políticas que subyacen al Estado Liberal o Legislativo, concretado principalmente en el Código de N apoleón, y por lo tanto, responde con coherencia, a la comprensión política y jurídica del paradigma que representa.

Lo anterior, a nuestro juicio, ha producido una verdadera crisis del principio de inexcusabilidad, que con el debilitamiento del Estado Legislativo frente al paradigma conocido como de Estado Constitucional, ha sufrido la pérdida de su relevancia, provocando una serie de problemas, que a nuestro ver, se originan de la incompatibilidad de la actual configuración del derecho, con los ideales con los cuales se fijó su tradicional alcance, que

\footnotetext{
31 ACtas de la "Comisión OrtúZaR", Sesión 304 de 6 de julio de 1977, pp 1349-1354, disponible en http:// www.bcn.cl/lc/cpolitica/actas_oficiales-r [última revisión, 5 de abril de 2011].

32 Aldunate (2009) p. 491.

${ }^{33} \mathrm{~N}$ os referimos a los ya citados artículos $76^{\circ}$ de la CPR, $10^{\circ}$ del COT, $170 \mathrm{~N}^{\circ} 5$ del CPC y 24 del CC.
} 
hace necesario buscar una adecuada comprensión del referido principio, atento a su historia y al texto normativo en que descansa, y debidamente enfocado desde la perspectiva del Estado Constitucional, a fin de compatibilizarlo a las exigencias y necesidades actuales.

Para ello, en primer lugar, intentaremos justificar el uso del término Estado Constitucional, frente al paradigma del Estado Legislativo al Constitucional, y la manera en que el tránsito de un paradigma a otro, ha modificado la comprensión de conceptos como el de jurisdicción, para luego describir como las nuevas exigencias del Estado Constitucional, han producido problemas de compatibilidad con la comprensión de la inexcusabilidad, provocando su pérdida de relevancia, para finalmente, proponer una reformulación del principio.

\subsection{Estado Constitucional: una opción metodológica}

Estamos conscientes que el término Estado Constitucional puede resultar ambiguo, ello, por la cantidad de autores que utilizan la referida expresión, cada uno con un énfasis distinto, por lo mismo, hemos hecho la opción metodológica de seguir en este punto a Luiz Guilherme MARINONI ${ }^{34}$, para quien - siguiendo principalmente a Alexy, y también de cerca a ZAGREBELSKY ${ }^{35-}$, el Estado Constitucional sería aquel paradigma que surge del reemplazo del viejo principio de legalidad, "donde la subordinación de la ley es reemplazada por la subordinación a la Constitución (...) en la subordinación de la propia legislación a la Constitución"36, que obliga a enfrentar al derecho en general, su concepto, instituciones y contenidos, a los criterios constitucionales ${ }^{37}$.

Así, en la visión del profesor MARINONi, el nuevo paradigma importa una comprensión del derecho ya no más a partir de la ley, sino a partir de la Constitución, afirmación que adquiere una amplitud mayor frente a la distinción normativa entre reglas y principios ${ }^{38}$, y que con el aporte de la filosofía del lenguaje, diferencia el texto normativo (referido a las formas gramaticales en que se expone), y la norma que se extrae de aquellas formas lingüísticas, en cuanto construcción que realiza el intérprete en su proceso de comprensión del texto en que se concreta, a la luz de los derechos fundamentales.

Se plantea como característica del Estado Constitucional, la centralidad de los de rechos fundamentales como categoría nueva, tan alejada del positivismo clásico como del iusnaturalismo, por cuanto se encuentran fundados en una comprensión pluralista de la sociedad y en el principio democrático deliberativo, donde el legislador se encuentra limitado por los contenidos esenciales de dichos derechos, los que sirven de punto de arran-

\footnotetext{
34 Marinoni (2006) y Marinoni et al. (2010).

35 Zagrebelsky (2003) p. 34. y Marinoni (2006), especialmente el capítulo tercero.

${ }^{36}$ Marinoni (2006) p. 45: Traducción libre de: “(... ) a subordinação à lei passou a significar subordinação à Constituição, ou melhor, que a subordinação do Estado à lei foi levada a uma última conseqüencia, consistente na subordinação da própria legi slação à C onstituição, que nada mais seria do que a 'lei maior'".

${ }^{37}$ Zagrebelsky (2003) p. 34.

38 Terminología principalmente desarrollada por Ronald DwoRkin y la elaboración posterior de Robert Alexy. Seguimos en este punto el trabajo de Atienza y Ruiz (I99i), en cuanto considera las reglas y principios como especies del género "norma", cuya diferencia podría radicar en el grado de generalidad o indescripción semántica entre unas y otras.
} 
Martínez Benavides, Patricio — “El principio de inexcusabilidad y el derecho de acción..."

que en la labor interpretativa y argumentativa39, imprescindibles en la labor tanto judicial como legislativa en su relación con textos normativos.

El Estado Constitucional, al superar la identidad entre derecho y ley que propone el Estado Legislativo, busca una recomposición armónica entre ambos conceptos, para lo cual, la Constitución otorga un contenido sustantivo que obliga a enfrentar la norma, conforme a los principios de la Carta Fundamental, entendiéndose el derecho como algo dúctil ${ }^{40}$, que requiere de la labor jurisprudencial para darle formas definidas y concretas.

\subsection{El tránsito del Estado Legislativo al Estado Constitucional}

El cambio de paradigma a que se hace referencia, corresponde a un reemplazo progresivo de valores y núcleos de base que hasta hace poco eran indiscutidos ${ }^{41}$.

La modernidad y su proyecto, específicamente el referido a los ideales ilustrados, concretados con el denominado Estado Liberal o Legislativo, fue severamente cuestionado a consecuencia de la llamada revolución industrial, y muy especialmente a partir de las barbaries ocurridas con ocasión de la Segunda Guerra M undial.

Sus críticas se agrupan preferentemente en lo que se ha denominado pensamiento "posmoderno", entendido como una postura que es escéptica frente a la pretensión moderna de universalidad: de la razón fuerte, y del progreso indefinido42, que se caracteriza por su actitud de desconfianza frente a los absolutos y a los valores ilustrados, pues predican "el fin de los metarrelatos" y la posición de "que uno no les otorga más crédito a los metarrelatos" 43 , de modo que se sitúa crítica y escéptica frente a los valores de la ideología del Estado Legislativo.

El derecho, como ciencia ligada a lo social, se ve necesariamente afectada por los cambios que se verifican en dicho ámbito; lo jurídico, a partir de aquí, comienza ha sufrir notables modificaciones, especialmente en las áreas de la teoría del derecho.

El ataque se dirige preferentemente contra el positivismo jurídico y su formalismo concretado en su identificación del derecho con la ley, y especialmente, contra el principio o ficción de la igualdad formal, que comienza a ser despreciado por su lejanía con la realidad material, la que se caracteriza justamente, por corresponder a un mundo profunda y esencialmente desigual o plural, y que el Estado Legislativo ha optado por ignorar.

Se remece con ello, el principio de supremacía de la ley y de igualdad formal, especialmente con el surgimiento y relevancia que adquiere el denominado discurso de los

\footnotetext{
39 TeJADA (1999).

40 ZAGREBELSKY (2003).

41 Utilizamos el término "paradigma", en el concepto utilizado por Echeverría (1997), quien basado en Thomas Kunn, lo define como "matriz de distinciones primarias a través de las cuales se define lo que es real, la capacidad de conocimiento de los hombres, el sentido de la existencia y las posibilidades de la acción humana, los criterios de validez argumental, la estructura de nuestra sensibilidad".

42 Lyotard (1999) p. 23 señala que posmodernismo "no es el fin del modernismo, sino su estado naciente". Por su parte, Welsch (1997) p. 36, señala que posmodernidad no es una determinación temporal, "sino un nuevo enfoque, una actitud espiritual distinta".

43 WeLsch (1997) p. 37.
} 
derechos humanos ${ }^{44}$, que obligan a un replanteamiento de los conceptos de teoría del derecho y de filosofía política, y también, por qué no, del derecho procesal.

Se cuestiona asimismo, la denominada razón fuerte, y su pretensión monológica de obtención de la verdad, que olvidó el uso de la razón práctica, y sobre todo, el contenido de la decisión, y su exigencia de "justicia", lo que a nuestro juicio se justifica por la estructura del derecho procesal clásico, que se despliega a partir del "conflicto", donde el protagonista es la sentencia que soluciona la controversia, por lo que su finalidad va dirigida a la certeza jurídica formal 45 .

Por ejemplo, Marinoni plantea que el concepto de derecho en el Estado Legislativo se caracteriza por el recurso a la ley a través del principio de la legalidad, entendida esta como acto supremo revestido de legitimidad, que en definitiva, en vez de abolir el absolutismo contra el cual se alzó, reemplazó el absolutismo del Rey, por el de la Asamblea Parlamentaria ${ }^{46}$, lo que permitió la identificación del derecho con la ley ${ }^{47}$. Lo que finalmente repercutiría en el propio concepto de jurisdicción y por supuesto, en todo el derecho procesal.

Así, el derecho procesal encuentra su fundamento en esta comprensión del derecho, como también, en la ficción de la igualdad de los litigantes - que Marinoni critica por su indiferencia ante las distintas posiciones sociales concretas de las partes, que justifican la uniformidad procedimental48-, y en la verdad formal del proceso49, en oposición al concepto de verdad material. Frente a este dualismo, aparece como indiferente a la larga, el contenido de la decisión, mientras respete el formalismo aludido, y resuelva el conflicto.

D e esta manera, las críticas que surgen en contra de la modernidad, en el contexto del mencionado cambio de paradigma, obliga a enfrentar el derecho procesal frente a estos nuevos elementos: la actual cultura de los derechos fundamentales ${ }^{50}$, y la supremacía de la Constitución, además del resurgimiento de la razón práctica de la mano de la retórica y de la comprensión del derecho como argumentación, en cuanto factor de legitimación de las

\footnotetext{
44 Rabossi (1990) refiriéndose por tal a la cultura que surge a partir de la D eclaración de los Derechos del $\mathrm{H}$ ombre de las $\mathrm{N}$ aciones Unidas del año 1948, fundada en la positivización internacional de los mismos, que pretende consagrar a nivel planetario una serie de principios y valores, inicialmente reconocidos a los individuos respecto los Estados, de tan alto valor, que pueden ser reclamables incluso internacionalmente, pues se reconocen de alcance universal.

45 Ver al respecto, Marinoni (2010).

46 Marinoni (2005): "N esse sentido se pode dizer que na Europa Continental o absolutismo do rei foi substituido pelo absolutismo da Assembléia Parlamentar (... ) embora substituindo o rei, manteve o absolutismo por meio do principio da legalidade". p. 14.

47 Alvaro de Oliveira (2008) p. 36.

48 Marinoni (2004) p. 57.

${ }^{49}$ TARUfFo (2008a) y TARUfFo (2008b), autor que se muestra crítico frente al dualismo "verdad formal versus verdad material", proponiendo en la primera obra, que es "insostenible la idea de una verdad judicial que sea completamente distinta de la verdad tout court (... )", p. 24, y señalando en el segundo texto citado, que "Ios tribunales deberían establecer la verdad de los hechos $(\ldots)^{\prime \prime}$, sin realizar una diferencia entre verdad formal y material.

${ }^{50}$ Rabossi (1990). Como ya se mencionó, Rabossi utiliza el concepto de cultura de los derechos humanos, para afirmar que dicho paradigma corresponde a un hecho de la causa, que por lo mismo, no exige justificación dogmática. ver RoRTY (2000) p. 223.
} 
decisiones estatales; elementos que integran el denominado Estado Constitucional, como nuevo paradigma de comprensión del derecho.

Para Atienza y Ferrajoli, algunos de los factores que explican esta relación entre Argumentación y Constitución, son por un lado, justamente las características de este tránsito del "Estado Legislativo" al "Estado Constitucional"51, y por otro, la validación de los procesos democráticos, que exigen el consentimiento de los ciudadanos, para su legitimación, lo que ha traído como consecuencias, los movimientos y tendencias de aplicación directa de la Constitución, la constitucionalización de los derechos subjetivos privados, y la aparición de teorías que por ejemplo, reconocen la horizontalidad de la aplicación de los derechos fundamentales, que exigen del órgano legislativo, especialmente del judicial, una justificación racional de sus decisiones "como característica esencial de una sociedad democrática" 52 .

\subsection{La COMPRensión de La JURisdicción: del Estado Legislativo al Estado} Constitucional

En el caso específico del derecho procesal, el Estado Constitucional impulsa a entender la labor judicial de manera diferente a la tradicional del Estado Legislativo, esto es, dejando de lado la resolución de conflictos entre particulares como eje central de la función jurisdiccional.

No es que se niegue la importancia histórica de la necesidad de la eliminación de los conflictos jurídicos entre privados, que en definitiva explica la conformación histórica de la función jurisdiccional y del Estado mismo53, sino que se desplaza dicho fin a una categoría de objetivo importante, pero eventual, no definitorio del ejercicio jurisdiccional.

En efecto, la perspectiva del Estado Constitucional, reprocha que el objeto principal del ejercicio de la función jurisdiccional, sea la resolución estable de los conflictos jurídicos, pues el bien que se intenta lograr con ello, es en definitiva, otorgar certeza jurídica en la dimensión privada de actuación de los individuos, finalidad a la que en estricto rigor, le es indiferente e irrelevante el contenido de la solución.

Esto lo ilustra claramente M ichele TARUfFo, al criticar la visión señalada, al decir: “(...) la forma en que el juez resuelve la controversia no importa realmente: podría incluso resolverla lanzando una moneda al aire"54, descripción que es coherente con el paradigma del liberalismo postrevolucionario, pues en el marco de un Estado que se funda en la igualdad de los individuos, la jurisdicción debe considerar a las partes en abstracto, para lo cual se necesita un procedimiento judicial neutro, ciego y en lo posible único, a fin de alejarse de la realidad práctica, y operar en el nivel de las ficciones políticas, como lo es el

\footnotetext{
51 Atienza y Ferrajoli (2005) p. 10, quienes conceptualizan Estado Constitucional como aquel que contiene primero, una distribución formal del poder; segundo, que reconoce derechos fundamentales que limitan la producción, interpretación y aplicación del derecho; y finalmente, que contempla mecanismos de control de constitucionalidad, que "supone el sometimiento completo del poder al derecho, a la razón: a la fuerza de la razón".

52 Atienza (2007) p. 132.

53 Marinoni y Arenhart (2007) p. 31.

54 Taruffo (2008b) p. 21.
} 
ya mencionado principio de igualdad, por lo que el contenido de la solución, no será un punto relevante frente a la fuerza de cosa juzgada con que se revisten las decisiones jurisdiccionales, que soluciona con estabilidad el conflicto.

La mirada del derecho procesal desde la perspectiva del Estado Constitucional también obliga a considerar por ejemplo, la importancia material de la "prueba", en cuanto proceso de establecimiento concreto de los hechos materia de un proceso - superando la forzada distinción entre verdad formal y material55_, y principalmente, la relevancia de la justificación de las decisiones judiciales, frente a la rehabilitación de la razón práctica y el uso de la argumentación y retórica, lo que reconduce al interesante problema de la posibilidad de la búsqueda de la decisión justa.

En definitiva, el cambio de paradigma implica una reformulación de los conceptos procesales, coherente con los ideales representativos de cada uno de ellos.

Entre nosotros, la comprensión de la función jurisdiccional ha seguido de modo general la visión propia del Estado Legislativo, a pesar de que los textos constitucionales y legales en que se configura el tema, no dicen alusión directa a la resolución del conflicto como elemento central.

En efecto, en nuestro país, el concepto de Jurisdicción se encuentra básicamente en dos textos que utilizan una redacción similar: el artículo $1^{\circ}$ del COT y el artículo 76 de la CPR, caracterizada básicamente como "facultad" estatal, para conocer causas civiles y criminales, juzgar y hacer cumplir lo juzgado.

La comprensión de dichos textos que ha tenido mayor aceptación en la doctrina nacional, es considerar a la jurisdicción no solo como facultad, sino como poder-deber, destinado al objetivo de resolver controversias o litigios entre particulares (a pesar que dicha dupla conceptual, se incluye en la voz "función"56).

Como ejemplo de ello, tenemos la ya clásica definición de Francisco Hoyos HenreCHsoN $^{57}$, quien entiende la jurisdicción, como un "poder-deber" del Estado, cuyo objetivo es la "resolución de conflictos", incluyendo en dicha definición, el principio de la inexcusabilidad, al señalar que el "ejercicio de la jurisdicción es necesario (...) en todos aquellos casos en que fueren inadmisibles las soluciones autocompositivas y en que por lógica consecuencia, la autotutela estuviere prohibida (...) la inexcusabilidad, que no pasa de ser el reverso de la misma medalla, se da por que el Estado, a través de sus órganos jurisdiccionales, no puede permitir que los entuertos perduren" 58 .

En el mismo sentido, encontramos la también conocida definición de Juan Colomво Campbell, quien destaca la expresión poder-deber, y la resolución de conflictos, como elementos esenciales de justificación de la jurisdicción, al señalar que aquella "es el poder deber que tienen lo tribunales para conocer y resolver, por medio del proceso y con efecto de cosa

\footnotetext{
55 NúNEEZ (2008).

${ }^{56}$ Chiovenda (2001) p. 250. Por ejemplo, en la definición de jurisdicción que formula, se entiende la voz "función", justamente como una facultad obligatoria del órgano público pertinente, que en su opinión, consiste en la actuación de la voluntad de la ley, en cuanto la "actividad jurisdiccional es siempre una actividad de sustitución, y precisamente la sustitución por una actividad pública de una actividad de otro".

${ }^{57}$ Hoyos (1978) p 77.

${ }^{58}$ Hoyos (1978) p. 90
} 
Martínez Benavides, Patricio — "El principio de inexcusabilidad y el derecho de acción..."

juzgada, los conflictos de intereses de relevancia jurídica que se promuevan en el orden temporal, dentro del territorio de la República y en cuya solución les corresponda intervenir"59.

C reemos que esta visión de la jurisdicción y su vinculación principal a la resolución de conflictos, desnaturaliza su sentido, pues olvida el sentido cardinal y originario de la actividad del derecho, que es la respuesta a la aporía fundamental judicial: "la cuestión de qué sea lo justo aquí y ahora"60.

D esde esa perspectiva, la jurisdicción debe ser comprendida de una manera en que se acerca a su fórmula histórica más clásica, esto es, como aquella labor destinada a declarar el derecho.

Por eso nos parece más coherente con una visión desde el paradigma del Estado Constitucional, una concepción de jurisdicción, sustentado en el proceso de adjudicación del derecho -que de manera consecuencial y lateral, eventualmente puede solucionar un conflicto-, por lo que la función jurisdiccional consistiría en "aplicar la ley a los casos individuales tomando como base criterios objetivos y buscando el interés de la justicia (...) una decisión legal y justa (... )"61.

En efecto, recalca Taruffo, el hecho de que se solucione un conflicto, no implica que aquella resolución sea una buena decisión, pues para que sea tal se hace menester que la decisión goce de legitimidad, para lo cual es indispensable la determinación de los hechos reales del caso concreto, en el contexto de un proceso legítimo62.

Una opinión similar expresa De la Oliva, al indicar que "lo esencial de la función jurisdiccional no es disolver discrepancias o resolver controversias"63, sino que lo propio de la jurisdicción es la tutela y la realización del derecho objetivo.

De esta manera, en el Estado Constitucional, el ejercicio de la jurisdicción ya no identifica el derecho con la ley y su mecánico ejercicio de subsunción, sino que se busca su aplicación en una comprensión de la misma, en cuanto rol adjudicador, que derechamente declara el derecho objetivo, todo esto, a la luz de los principios procesales y sustanciales contenidos en la Constitución, principalmente, subordinándose a los derechos fundamentales.

Siguiendo esta idea, Marinoni propone una nueva formulación al concepto de proceso, replanteando su naturaleza, al indicar que en estricto rigor le corresponde un rol que no debe olvidar su misión instrumental, en cuanto búsqueda de la protección de los derechos, mediante la comprensión de la ley en la dimensión de los derechos fundamentales ${ }^{64}$, esto es, la labor jurisdiccional se encuentra condicionada por dicha dimensión.

Surgen así nuevas vetas a considerar en el ámbito del derecho procesal, pues se hace menester en este ámbito, tener en cuenta también, por ejemplo, las técnicas de delibera-

\footnotetext{
59 Cоlombo (1991) p. 41.

60 VIEHWEG (1964) p.129.

61 Taruffo (2008b) p. 20.

62 Ver Del Claro (2009) p. 22, citando el ejemplo de Pérez Ragone, Álvaro, en Contornos de la Justicia Procesal (Procedural fairness), referente al caso de Robin $\mathrm{H}$ ood, quien roba de los ricos para dar a los pobres, donde si bien el resultado podía ser materialmente justo, las "técnicas procesales" con que llegaba a tal resultado (robar), no lo son, lo que nos propone una identidad entre la justicia material y la procesal.

63 De la Oliva (2008).

64 Marinoni (2004) p. 405.
} 
ción como agentes de legitimación en el contexto de las exigencias del Estado Constitucional y de los derechos fundamentales, específicamente de cara a las bases que deben regular la participación de las partes en el proceso, en la actividad persuasiva dirigida al órgano jurisdiccional, y también, respecto la fundamentación de las decisiones jurisdiccionales, como obligación de argumentación que recae sobre el juez para legitimar su decisión ${ }^{65}$, todas ellas, características que deben entenderse incluidas en el proceso de adjudicación jurisdiccional.

M ayor claridad en este punto, han demostrado autores como Robert G. Bone, quien basado en el marco teórico de Ronald Dworkin, propone una comprensión del papel jurisdiccional, partiendo de un acercamiento al rol judicial, basado en el producto del proceso, señalando que el propósito primario de la jurisdicción corresponde a la aplicación de la ley substantiva, en un marco que incluye todas las decisiones efectuadas durante el curso del procedimiento, de las cuales depende la adjudicación y aplicación del derecho de fondo ${ }^{66}$.

Por su parte, ENDicotT, recalca que este proceso de adjudicación, conforma "una exigencia formal y estructural" ${ }^{67}$ dirigida al juez, que caracteriza una obligación y una necesidad de pronunciamiento o resolución.

El mismo concepto encontramos en H. L. A. Hart, quien luego de plantear su concepto de derecho como unión de reglas primarias y secundarias, señala que estas últimas, en lo que corresponde a una descripción del rol judicial, son aquellas que otorgan facultades individuales para hacer determinaciones autoritativas respecto si en una ocasión particular, una regla primaria ha sido contravenida68.

Jeremy WaLdron cita también la opinión de M artin Shapiro, quien señala que la actuación de un tribunal se caracteriza por involucrar a un funcionario con la autoridad de hacer una determinación 69.

No es el momento de referirnos a la evolución histórica del concepto de jurisdicción, pero consideramos importante, no confundir la propuesta anterior, con las visiones de autores como Chiovenda o CaRnelutTi ${ }^{\circ}$, por eso nos parece adecuada la precisión formulada por Marinoni, al comprender la función jurisdiccional en el Estado Constitucional, como aquella destinada a la tutela efectiva de los derechos, pues la jurisdicción, tiene el "deber de aplicar la ley en la dimensión de los derechos fundamentales, haciendo siempre el rescate de los valores substanciales en ellos contenidos. Tutelar los derechos, en otras palabras, es aplicar la ley, frente a situaciones concretas, a partir de los derechos fundamentales" 71 , siendo dicha función, aquella que integra las esferas de los derechos materiales y del derecho procesal.

\footnotetext{
${ }^{65}$ Marinoni et al. (2010) pp. 106 y 127 y sS.

66 Bone (2010).

${ }^{67}$ Endicott (2006) p. 292.

68 Ver WaLdRon (2010) citando a HarT, H . L. A., en The concept of law, p. 96.

69 Ver Waldron (2010), citando a Shapiro, M artin, en Courts, a comparative and political, p. 13, traducción libre de "(... ) officer with the autorithy to make a determination".

70 Por todos, Marinoni (2004) p. 90 y ss.

71 Marinoni (2004), p. 138. Traducción libre de: “(... ) dever de aplicar a lei na dimensão dos direitos fundamentais, fazendo sempre o resgate dos valores substanciais neles contidos. Tutelar os direitos, em outros termos, é aplicar a lei, diante das situacoes concretas, a partir dos direitos fundamentais".
} 
Además, el paradigma del Estado Constitucional, pretende superar la ficción de la igualdad formal constitutiva del paradigma anterior, de modo que el ejercicio de la jurisdicción en dicho contexto, solo se justifica en la medida que considere las necesidades concretas del derecho material que se reclama ${ }^{72}$, pues su función es la tutela efectiva de los derechos, comprendidos bajo el prisma de los derechos fundamentales: esto es, la tutela y la realización del derecho objetivo ${ }^{73}$, la que en sí, se constituye en un derecho fundamental por sí misma ${ }^{74}$.

Interesante es la reflexión que sobre el punto realiza Áluvaro de Oliveira, quien señala que no basta elevar la tutela jurisdiccional a nivel constitucional, sino que es necesario remarcar que esta debe ser eficaz ${ }^{75}$, lo que se relaciona con las herramientas procesales con que cuenta el juez, para dar efectividad al derecho material cuya tutela se reclama, encontrándose en dicha perspectiva, sobrepasada e insuficiente para ello, la sola dictación de una sentencia - sea que condenatoria o declarativa-, pues el derecho objetivo se encuentra satisfecho no con la sentencia que lo declara ni que ordena su cumplimiento, sino que se satisface con la prestación in natura, con la ejecución de lo específicamente debido.

Es por lo anterior que se sostiene, que el Juez debe tener a su arbitrio la posibilidad de construcción pertinente de la herramienta procesal, que tutele efectivamente el derecho material que se reclama, teniendo en cuenta, desde la perspectiva de los derechos fundamentales, tanto la posición del actor, como del demandado, pues como señala Marinoni: "la función del juez no es solo la de dar a luz la norma jurídica aplicable, sino la de tutelar de manera concreta el derecho material (... para lo cual debe...) utilizar el procedimiento y la técnica idónea a la efectiva tutela del derecho material"76.

En síntesis, creemos que una concepción coherente con el Estado Constitucional, nos lleva a considerar la jurisdicción, como la función estatal de dar aplicación a la ley en el caso concreto, a partir de los derechos fundamentales ${ }^{77}$, teniendo en cuenta, e incluyendo en su contenido conceptual, su objetivo de dar tutela efectiva a los derechos materiales reclamados.

Lo aclaran mejor Marinoni, Pérez Ragone y Núńez Ojeda, al señalar que la jurisdicción en el Estado Constitucional, significa "aplicar la ley, en las situaciones concretas, a partir de los derechos fundamentales"78, lo que evidentemente excede de la visión de la jurisdicción como tutela de los derechos subjetivos, en cuanto solución del conflicto derivado de la violación de un derecho subjetivo privado, sino que comprende dicha función, como aquella destinada a "viabilizar las tutelas prometidas por el derecho material"79, esto es, labor de adjudicación del derecho, en cuanto busca integrar los planos del derecho

\footnotetext{
72 Marinoni (2004) p. 109.

73 De la Oliva (2008) p. 21.

74 Ver GonZÁlez (1984).

75 Álvaro de Oliveira (2008) p. 153.

${ }^{76}$ Marinoni (2004) p. 133, traducción libre de "a função do juiz nao é apenas editar a norma juridica, mas sim a de tutelar concretamente 0 directo material (...) 0 juiz tem o dever de utilizar o procedimento e a técnica idonea à efetiva tutela do directo material".

${ }^{77}$ Marinoni (2004) p. 138.

${ }^{78}$ Marinoni et al. (2010) p. 134.

${ }^{79}$ Marinoni et al. (2010) p. 136.
} 
material prometido y del derecho procesal "mediante las líneas de la Constitución y de los derechos fundamentales" 80 .

\subsection{LA PÉRdida DE RELEVANCIA DE LA INEXCUSABILIDAd EN LA PERSPECTIVA DEL}

Estado Constitucional

Sostenemos que la comprensión restringida del principio de inexcusabilidad, que ha sido limitada como regla de prohibición del non liquet, en cuanto cláusula que justifica la apertura a la equidad como fuente del derecho, solo se justifica en un ámbito de comprensión legalista del derecho.

En efecto, el principio de inexcusabilidad viene a complementar dentro del contexto del Estado Legislativo, el rol jurisdiccional del Estado, el que luego de haber monopolizado la resolución estable de los conflictos excluyendo la autotutela, garantiza por su intermedio, el cumplimiento de la obligación funcionaria del pronunciamiento judicial.

Lo anterior, en un contexto jurídico, que reconoce y considera la posibilidad de conflictos cuyas respuesta o resolución han sido omitidas por el legislador, de lagunas legales que de no contar con la flexibilidad necesaria, impediría el cumplimiento de la obligación de fallar, y con ese fin, se autoriza al juez, de modo excepcional, a crear una norma, que solucione el caso concreto y rellene el vacío legislativo, mediante el recurso a la jurisdicción de equidad.

Así por lo menos, como hemos dicho, lo plantea la doctrina chilena tanto procesal como constitucional, en estrecha similitud, con la comprensión francesa de la prohibición del non liquet y el deber de fallar, que según afirmamos, sería el fundamento histórico más próximo en nuestro sistema.

Sin embargo, el advenimiento del paradigma del Estado Constitucional nos propone una comprensión del derecho diferente a la que perfiló de la señalada manera el principio de inexcusabilidad, al implicar en cierto modo, una superación del principio de la supremacía de la ley, invitando a una comprensión del derecho menos rígida que la visión legalista del Estado Legislativo, "dúctil", que partiendo de la aceptación, de que los sistemas normativos se encuentran compuestos de reglas y principios ${ }^{81}$, es posible reconocer tras la norma un contenido valórico, de las cuales surge y se distingue una racionalidad propia, esto es, un "derecho implícito"82.

Así considerado el derecho, este se constituye en un sistema donde siempre es posible integrar una respuesta a cada cuestión concreta puesta en conocimiento de los tribunales, y que aunque no haya norma expresa, es posible construir una solución conforme a

\footnotetext{
${ }^{80}$ Marinoni et al. (2010) p. 137.

81 ZaGRebelsky (2003) p. 109: "Si el derecho actual está compuesto de reglas y principios, cabe observar que las normas legislativas son prevalentemente reglas, mientras que las normas constitucionales sobre derechos y sobre la justicia son preval entemente principios (... ) Por ello, distinguir los principios de las reglas significa, a grandes rasgos, distinguir la Constitución de la ley".

82 Laporta (2002).
} 
derecho, teniendo presente el contenido valórico o racional implícito que fluye del sistema normativo, y en su defecto, desde los contenidos constitucionale ${ }^{83}$.

Así, la regla de la inexcusabilidad - en su comprensión restrictiva, insistimos- pierde importancia y relevancia en el Estado Constitucional, pues en dicho paradigma no parece plausible hablar de vacíos legales o ausencia de ley decisoria litis en esos términos, pues justamente la obligación que contiene el referido paradigma, de interpretar el derecho conforme a los principios de contenido constitucional y de los derechos fundamentales, excluye dicha posibilidad.

Con un derecho comprendido como dúctil, encontrar una solución conforme a derecho, sea que se contemple expresa o sea que fluya del contenido implícito del ordenamiento jurídico, se hace posible sin necesidad de una norma excepcional de apertura a la jurisdicción de equidad, que hace desde ese punto de vista, inútil el principio de inexcusabilidad, pues en estricto rigor, nunca va a existir un caso en que se presente tal defecto de ley que no sea reconducible a una solución construida a partir de los principios explícitos e implícitos del sistema jurídico del Estado Constitucional, y en última instancia, de los derechos fundamentales.

\section{LA PERSPECTIVA DEL ESTADO CONSTITUCIONALY EL PRINCIPIO DE INEXCUSABILIDAD}

\subsection{El derecho procesal frente a las exigencias de los derechos} FUNDAMENTALES

Como ya hemos señalado, la marca original del Estado Constitucional, es la posición que ocupa la ley, especialmente en su vinculación con el juez, que en dicho paradigma se caracteriza por encontrarse sometida al escrutinio de adecuación y subordinación a los contenidos constitucionales ${ }^{84}$, que se concretan especialmente en la primacía de los derechos constitucionales por sobre la ley.

Por otro lado, también señalamos como uno de los factores históricos que impulsaron el cambio al paradigma del Estado Constitucional, la irrupción de los regímenes totalitarios que terminaron provocando los horrores que acompañaron la Segunda Guerra M undial.

Desde el punto de vista del derecho procesal, la reflexión a que dichos acontecimientos históricos impulsan, fue la necesidad de incluir dentro del catálogo de derechos fundamentales o humanos ${ }^{85}$, las denominadas garantías procesales, en un interesante proceso histórico que definió de alguna manera la distinción - aún brumosa por lo demás86_ entre derechos sustantivos y derechos procesales.

\footnotetext{
83 Situación que amplía la obligación argumentativa del juez en sus decisiones, del mero convencimiento del juez, a la necesidad de justificar la racionalidad de sus decisiones en el caso concreto, frente a diversos auditorios, ver Marinoni et al. (2010) p. 106.

84 Zagrebelsky (2003) p. 34.

85 Solo para efectos metodológicos, se utilizará indistintamente la expresión derechos fundamentales o humanos, no obstante estar conscientes de la existencia de una nutrida bibliografía que los diferencia substancialmente.

86 Ver por ejemplo Solum (2005), p. 192 y 202.
} 
En nuestro país, no obstante las reformas procesales impulsadas en la justicia criminal, y especializada de familia y laboral, en cuyos cuerpos normativos se han consagrado dichas garantías de manera expresa, se mantiene vigente la crítica que en el año 1997 realizara Alex Carocca, al acusar en nuestra Constitución un "defectuoso reconocimiento de los derechos humanos de contenido procesal"87 y particularmente, una carencia de herramientas que permitan su tutela directa, que ha hecho necesario recurrir a los Tratados Internacionales sobre $\mathrm{D}$ erechos $\mathrm{H}$ umanos, para integrar a nuestro derecho garantías que en el esquema propuesto por el autor mencionado, se clasifican en aquellas que garantizan la actividad de las partes, aquellas relacionadas con el ejercicio de la actividad jurisdiccional y finalmente las garantías del proceso.

Es en este sentido donde nos parece más urgente replantearnos el principio de inexcusabilidad, adecuándolo a las exigencias de estos derechos fundamentales, teniendo en consideración que el desarrollo de los derechos procesales civiles se encuentran mayoritariamente consagrados en un nivel infraconstitucional, siendo tarea pendiente su reconocimiento constitucional, según el diagnóstico de Carocca, situación que al parecer también se repite en el sistema norteamericano según el testimonio de Robert G. Bone, al señalar, a propósito de la cláusula del debido proceso en el ámbito civil, a pesar de ciertos pronunciamientos a nivel de la Suprema Corte de dicho país ${ }^{88}$.

En la misma dirección, Pérez Ragone, califica como tarea pendiente justamente la constitucionalización de las etapas del proceso, específicamente la relativa a la ejecución89.

Nuestra propuesta se dirige justamente a sugerir el principio de inexcusabilidad, como soporte constitucional suficiente, de todos estos anhelos procesales, como intentaremos plantear posteriormente.

En dicho contexto, y frente al nuestro tema de la inexcusabilidad, nos parece de la mayor relevancia la consideración del derecho de acción, reformulado como derecho fundamental de acceso a la justicia, o a la tutela judicial efectiva, en la comprensión de que el órgano judicial es el primer obligado a integrar efectivamente aquellas garantías procesales consideradas como derechos fundamentales, y especialmente llamados a su respeto.

Para intentar justificar estas afirmaciones, nos parece adecuado dirigir nuestros esfuerzos, primeramente, a reformular la visión del principio de inexcusabilidad a la luz del Estado Constitucional.

\subsection{El PRINCipio de INEXCUSABILIAD, COMO "PRINCipio"}

En la propuesta de Ronald Dworkin, se establece el concepto de principio, como "un estándar que ha de ser observado, no porque favorezca o asegure una situación económica, política o social que se considera deseable, sino por que es una exigencia de la justicia, la equidad 0 al guna otra dimensión de la moralidad"90, que en dicho sentido genérico, pretende distinguir de las reglas, en cuanto estas últimas responden a una aplicabilidad

87 Carocca (1997) p. 32.

88 Bone (2010).

89 Pérez Ragone (2006a) p. 226.

${ }^{90}$ Dworkin (1989) p. 72 
disyuntiva, que obliga a un sí o un no, un todo o nada, mientras que los principios responden a una dimensión de peso e importancia, y que por lo mismo no pueden ser tratados como las reglas jurídicas, lo que se advierte principalmente en el proceso de decisión, donde no es posible invalidar un principio en favor de otro, proponiendo para ellos su ideal interpretativo del derecho como integridad, a través del mito del juez $\mathrm{H}_{\text {ércules }}{ }^{11}$.

Frente a este marco, surge la pregunta, de si es posible considerar el principio de inexcusabilidad como "principio" en el sentido dworkiniano.

Sí lo vemos exclusivamente desde la definición citada anteriormente, pareciera que sí, pues implica una exigencia de justicia o de moralidad estatal - no queremos entrar en el complejo tema de la moralidad en el ámbito jurídico- , que los derechos sean efectivamente tutelados, y específicamente, que frente al requerimiento de los tribunales de ejercer su rol adjudicador, estos lo hagan sin excusas.

\subsection{EL PRINCIPIO DE INEXCUSABILIDAD COMO MANDATO DE OPTIMIZACIÓN}

D entro de la concepción del Estado C onstitucional, algunos autores han adoptado la fórmula de Robert Alexy ${ }^{92}$, para caracterizar los principios constitucionales como "mandatos de optimización", en cuanto obligaciones que le corresponden al Estado en su conjunto, en cuanto deber positivo, de promover los derechos y principios constitucionales.

Recordemos que para el mencionado autor, las normas son distinguibles entre reglas y principios, y la diferencia fundamental entre ambas, es que los últimos corresponden a normas que "ordenan que algo sea realizado en la mayor medida posible, dentro de las posibilidades jurídicas y reales existentes" 93 , añadiendo que los principios además, pueden referirse tanto a derechos individuales como colectivos, pero que se caracterizan como razones prima faci $e^{94}$.

Por otro lado, y con el objeto de caracterizar el concepto de "optimización", Alexy subraya el hecho de que la teoría de los principios se encuentra necesariamente ligada con el principio de proporcionalidad 95 .

En efecto, el subprincipio de adecuación o idoneidad junto con el de necesidad (del medio más benigno) se derivan del carácter de los principios como mandato de optimización en el ámbito de las posibilidades concretas o fácticas, mientras que el subprincipio de la proporcionalidad (en sentido estricto), se refiere a las posibilidades jurídicas de optimización ${ }^{96}$.

En dicho contexto, creemos que la inexcusabilidad, es perfectamente reconocible como principio en la terminología antes propuesta, y como tal, puede reconducirse en dicho sentido, como un mandato de prima facie (no definitivo), que busca la máxima realización, en este caso específico, de la posibilidad de acceso al pronunciamiento jurisdiccional, en otras palabras, con el derecho a la acción y de tutela efectiva de todos los derechos, lo que implica una comprensión amplia del principio de la inexcusabilidad.

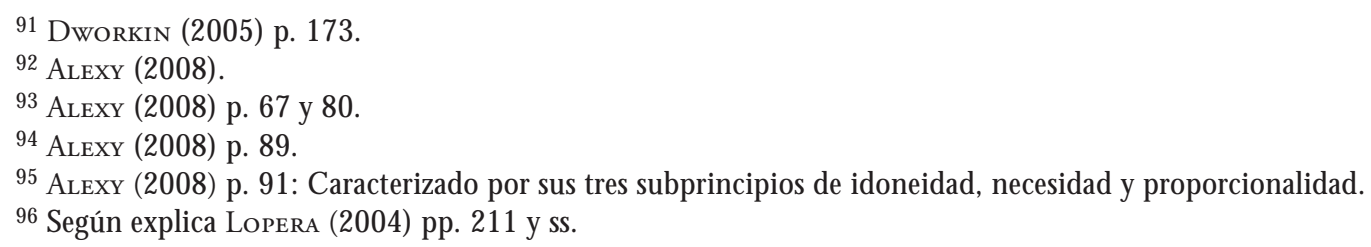


De este modo, el principio de la inexcusabilidad, y su consagración constitucional, permiten caracterizarlo en el sentido propuesto, entendiendo que la optimización de los principios, según Alfonso García, sigue cuatro criterios objetivos ${ }^{97}$, a saber: graduabilidad (en cuanto exigen la realización del principio en el máximo grado posible), optimización (que busca el máximo grado de satisfacción posible), que sea ideal (correspondiente a un deber ser que sirve de guía para su cumplimiento, y de carácter prima facie (que implica que no es definitivo).

D esde esta óptica, identificada con los valores descritos del Estado Constitucional, se amplía el alcance de la inexcusabilidad, a una norma de carácter amplio que contiene un principio, que si bien obliga a prima facie al órgano judicial -pues se incluyó constitucionalmente en el capítulo que regula a dicho poder-, esconde en sí misma, de manera implícita, una faz positiva, que obliga al Estado en su conjunto, a su optimización.

En efecto, la propia redacción de los artículos 76 inciso segundo de la CPR y artículo 10 del COT, permiten esta conclusión, puesto que despliegan el principio de un modo más general y amplio que el que tradicionalmente se le otorga, incluso - pues utiliza la expresión "ni aún"- cuando no exista ley que resuelva el caso concreto.

Así, el deber que implica la mencionada norma, es un mandato de prestación inexcusable, que a la luz de los derechos fundamentales, se concreta en un imperativo de prestación de tutela efectiva de los derechos, identificable con el derecho de acceso a la justicia en el ámbito de la configuración de la acción procesal.

\section{EL PRINCIPIO DE INEXCUSABILIDAD Y EL DERECHO DEACCIÓN PROCESAL}

5.1. La aCCión procesal en Chile, una brevísima aproximación Crítica, y la PROPUESTA

Una visión del principio de inexcusabilidad compatible con el paradigma del Estado Constitucional, exige abandonar la raíz histórica moderna de su comprensión, que según hemos sostenido, se encuentra en la Francia del Code de $N$ apoleón, que comprendida como la simple prohibición del non liquet, se ha restringido entre nosotros, hasta considerarse solamente como una cláusula de excepción que autoriza integrar como fuente de derecho, la denominada jurisdicción de equidad, perdiendo relevancia frente a los cambios impulsados por el Estado Constitucional.

Para superar esta pérdida de relevancia -y corresponde al objeto de este trabajo-, se sugiere como propuesta concreta, dejar de lado el enfoque clásico del principio de inexcusabilidad, relacionado con el deber de fallar, y vincularlo con el derecho de acción procesal, comprendiéndolo no más como una cláusula de prohibición que concreta el mencionado deber, sino como el correlato constitucional orgánico de la acción, sobre el cual se estructura, entediendo la inexcusabilidad, como un "principio" en el sentido entregado por Dworkin y constituyéndose en un mandato de optimización en el sentido de Alexy,

${ }^{97}$ Lopera (2004) citando a García Figueroa, Alfonso, Principios y positivismo jurídico, p 211. 
indisolublemente unido al de acción procesal, en cuanto derecho fundamental a la tutela judicial y de acceso a la justicia.

Entre nosotros parece una cuestión pacífica asumir la naturaleza de la acción procesal como un derecho de carácter público subjetivo, que tiene un sustento constitucional, específicamente en el numeral $2^{\circ}$ del artículo 19 de nuestra CPR, al garantizar la igualdad ante la ley y principalmente en el numeral $3^{\circ}$ del mismo artículo, a propósito de la igual protección de los derechos y el derecho a la defensa jurídica98, que implica un deber estatal de tutela de los derechos - que son de naturaleza subjetiva-, de los individuos, donde la protección de los mismos no es un asunto sujeto a la voluntad del órgano del Estado competente, sino que pasa a configurarse como un deber ineludible, comprensión, que según Álvaro de Oliveira, la tutela que presta el órgano jurisdiccional no es un arbitrio del que el mismo dispone, sino que corresponde a una "protección imperativa (aunque pueda ser favorable o desfavorable) y no meramente al eatoria" 99 .

Tampoco han faltado los seguidores de Couture ${ }^{100}$, que han visto un fundamento directo del derecho de acción en el numeral 14 del artículo ya mencionado, que reconoce el derecho de presentar peticiones a la autoridad.

Sin embargo, tal como afirmamos anteriormente, nos parece que el tratamiento constitucional ha sido insuficiente en dos sentidos, primero, pues por un lado, no se ha adecuado a un concepto compatible con el paradigma del Estado Constitucional, que ha obligado a un replanteamiento del concepto de acción, entendiéndolo como derecho fundamental de acceso a la justicia o de tutela efectiva de los derechos.

Por otro, y en segundo lugar, nos parece que nuestra Constitución comete omisiones imperdonables que podrían desfigurar los contenidos a que se refiere la acción procesal, como por ejemplo, la falta de determinación de los derechos constitucionales referidos al proceso, como derechos procesales fundamentales, o principios de organización funcional, también, se observa un tratamiento deficiente a propósito del debido proceso, ya que por redacción del texto pertinente, las exigencias referidas al derecho al justo y racional procedimiento, como mandato orientado al legislador, que eventualmente excluiría al judicial de la posibilidad de exigencia del mismo ${ }^{101}$, y en lo referente al principio de inexcusabilidad, como acusa $\mathrm{CAROCCA}^{\mathrm{IO} 2}$, dicho deber, al ser exigible solamente al judicial, no impide la exclusión de asuntos del conocimiento del Poder Judicial, mediante, por ejemplo, un mandato legal.

Tampoco está asegurada de manera expresa, a nivel constitucional ${ }^{103}$, la tutela efectiva que debe otorgar el judicial, no obstante que el inciso segundo del artículo 38 de la CPR, consagra una norma que podría remediar parcialmente dicha omisión, al señalar que "C ualquier persona que sea lesionada en sus derechos por la Administración del Estado, de sus organismos o de las municipalidades, podrá reclamar ante los tribunales que determi-

\footnotetext{
98 Ver por ejemplo, Romero (2006) y Orellana (2006).

99 Álvaro de Oliveira (2009).

100 Couture (2001) pp. 4 y ss.

101 D eficiencia que es observada por Aldunate (2008) p. 201.

102 Carocca (1997) p. 36.

${ }^{103}$ Como parece ser la opinión de Bermúdez (2010).
} 
ne la ley, sin perjuicio de la responsabilidad que pudiere afectar al funcionario que hubiere causado el daño", pero como se observa, la norma solo se refiere a la lesión ocasionada por la Administración del Estado, y tampoco incluye la amenaza de lesión.

También se descubre como una carencia importante, la ya citada falta de desarrollo constitucional de la ejecución indicada por PéREz RAGONE ${ }^{104}$, quien subraya su importancia al señalar que la "ejecución integra el derecho fundamental de acción con las notas de adecuación y oportunidad"105.

Sin perjuicio de lo apuntado anteriormente, creemos que es posible una solución a estas deficiencias, mediante una comprensión amplia entendiéndola como un correlato orgánico del derecho de acción, que sirve de garantía para la tutela efectiva de los derechos, en cuanto corresponde a un principio que al informar la estructura orgánica y funcional del Poder Judicial, ingresa al sistema de principios y reglas, configurando nuestro derecho de modo explícito e implícito, mientras que al mismo tiempo que se despliega como una potestad o función pública, exigible subjetivamente, que se configura al mismo tiempo, en cuanto al alcance de su gestión y resultados, como un mandato de optimización.

Así, nuestra propuesta, es entender el principio de inexcusabilidad como algo más profundo que el de cláusula de integración de la jurisdicción de equidad, o en el mejor de los casos tradicionales, más profundo que el puro deber de fallar al cual se ha ligado históricamente. Proponemos entenderlo como contracara orgánica y funcional del derecho fundamental de la acción procesal en su comprensión más integral de derecho de acceso a la justicia, y de tutela efectiva de los derechos, integrando todos aquellos derechos procesales, que la doctrina ha comprendido como elementos del debido proceso en todas las etapas de la jurisdicción.

\subsection{La Inexcusabilidad COMO CONTRACARA DEL DeReCho FUndamental}

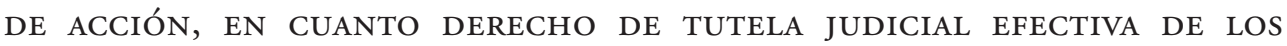
DERECHOS

Frente a las exigencias del Estado Constitucional, proponemos considerar la inexcusabilidad, como principio constitucional y como mandato de optimización, pero específicamente, considerando de modo primordial su ubicación en el texto constitucional, creemos que se despliega principalmente como el reverso orgánico del derecho fundamental a la acción procesal, en cuanto herramienta destinada a exigir la tutela efectiva de los derechos.

La construcción doctrinal que plantea la "autonomía" del derecho procesal, a través de la categoría de la acción procesal como independiente del derecho material, si bien en su momento permitió, según plantea Álvaro de Oliveira ${ }^{106}$, "reconciliar de forma automática y necesaria el derecho material (todos los derechos materiales) y la tutela jurisdiccional civil", la misma - en opinión del mencionado autor-, "ya no es satisfactoria", pues el concepto de acción de cara a los derechos fundamentales, y a la superación de la ficción

\footnotetext{
104 Pérez Ragone (2006a) p. 226.

105 Pérez Ragone (2006b) p. 496.

106 Álvaro de Oliveira (2009).
} 
de la igualdad formal, obliga a entenderla Ilanamente como un derecho fundamental en sí mismo, que no se puede limitar como simple "derecho formal de proponer o contestar una acción"107, sino que debe ser entendido de manera más amplia, en relación con el alcance del concepto de jurisdicción, esto es, como obligación estatal de tutelar efectivamente los derechos materiales, y por tanto, como una herramienta de eficacia de los derechos, de ejercicio estatal, y con un contenido complejo y dinámico a la luz del Estado Constitucional y la cláusula de debido proceso ${ }^{108}$.

Es en ese contexto y comprensión que la inexcusabilidad se puede alzar como el correlato oficial, en el ámbito del deber estatal, del derecho de recurrir en busca de tutela efectiva de los derechos, y que por lo tanto no se puede entender satisfecho con la solución del Estado Liberal de la simple resolución del conflicto jurídicamente relevante, pues en dicho paradigma, el deber judicial se agota con la sola posibilidad de exigir una decisión judicial, respecto la cual, el órgano correspondiente tiene el deber de pronunciarse, siempre en una sentencia que resuelve el conflicto, donde el proceso se manifiesta solo como la opción estatal, frente a la prohibición de la autotutela.

D e cara a los derechos fundamentales, el derecho de acción se acota a un contenido preciso y completo, que garantiza la materialización práctica del derecho objetivo, que exige una actividad eficiente en todas sus etapas, no girando alrededor de la sentencia (resolutoria de conflictos), sino utilizando como eje la tutela del derecho material reclamado.

Y lo anterior, porque el paradigma del Estado Constitucional, recupera el elemento práctico y tópico del derecho, pues como dice Pérez Ragone, "Ia jurisdicción pensada sin posibilidad de que lo decidido se cumpla actual o potencialmente, implica una negación del funcionamiento del Estado de D erecho", donde además, señala expresamente conforme lo veníamos afirmando, que se exige de la jurisdicción que "cuente con los medios idóneos para lograr material y no solo identificando la sentencia de condena como el punto final del ejercicio de la jurisdicción"109.

Es por estas razones, que creemos que no es posible incluir el derecho de acción como una especie dentro del género del derecho fundamental de petición, como propone Eduardo Couture ${ }^{\text {IIO }}$. Recordemos que dicho autor entiende "acción" como el "Poder Jurídico que tiene el individuo de dirigirse a los órganos de la jurisdicción", en cuanto "forma típica" del derecho constitucional de petición, entendido como "el derecho de comparecer ante la autoridad".

Al respecto, creemos que no se pueden confundir ambas instituciones, puesto que el derecho de petición corresponde a un derecho de carácter político, que garantiza el acceso ciudadano a ser escuchado por el Estado, y que tiene como principal característica, la informalidad y la amplitud (pues puede contener no solo peticiones, sino también, reclamaciones, denuncias, etc.), y que por regla general, tiene como destinatario a la administra-

\footnotetext{
107 MÜLler (2004) p. 130.

108 WaLdRon (2010) p. 4, propone una interesante lista de elementos del rule of law, complementaria a los principios formales propuestos por FulLer, que nos parecen relevantes en este punto.

109 Pérez Ragone (2006a) pp. 223 y 227.

110 Couture (2001) pp. 4 y sS.
} 
ción del Estado, cuyo correlato sería la obligación de respuesta de parte de la autoridad111; mientras que el derecho de acción, se configura como un derecho subjetivo público, cuya admisibilidad exige una serie de condiciones, y cuyo correlato, es justamente el deber de la inexcusabilidad dirigida al órgano judicial.

En dicho contexto, el derecho de acción debe incluir no solo la facultad de solicitar pronunciamiento de mérito 0 de fondo por parte del judicial, sino que debe entenderse como "el derecho a la efectiva y real viabilidad de la consecución de la tutela del derecho material (que) tiene como corolario el derecho a influir sobre el convencimiento del juez (y) exige la estructuración de técnicas procesales idóneas"112

$\mathrm{N}$ os parece que el principio de la inexcusabilidad es suficiente para sustentar una definición como la anterior, pues su redacción comprendida de manera amplia, implicaría una obligación del judicial, de no excusarse por motivo alguno de cumplir su función, ampliamente entendida, esto es, el otorgamiento debido de la tutela efectiva al derecho material.

La inexcusabilidad, de esta manera permite configurar dicha función, con el imperativo de que el órgano requerido, no puede excusarse de efectuar pronunciamiento de mérito, pero tampoco podría excusarse de no dar tutela al derecho, con la característica de efectiva, atendidas las circunstancias concretas en que se reclama, esto es, como derecho de acceso a la justicia, terminología más genérica que permite integrar el derecho a una prestación jurisdiccional atenta y consciente de la realidad y desigualdades materiales, que optimice el mandato de tutela efectiva mediante mecanismos aptos para su realización.

Julio Guilherme MüLleR, así lo propone, y lo caracteriza como una obligación estatal volcada a un "universo de consumidores del servicio público de prestación jurisdiccional que no conocen el establecimiento encargado de prestar dicho servicio, que no saben dirigirse a él, y que tampoco tienen consciencia de las constantes violaciones a los derechos de los cuales son titulares"113, comprensión que amplía aún más la obligación del Estado, extendiéndose a políticas extrajudiciales, como las relativas a la educación e información de los roles estatales, y la providencia de asesoría capacitada que concrete el acceso al servicio judicial.

\subsection{LA INEXCUSABILIDAD COMO DEBER DE RESPUESTA DEL ÓRGANO JUDICIAL}

Siguiendo lo anterior, podemos concluir que el derecho de acción, en su faz de de recho fundamental de acceso a la justicia, debe considerarse entonces, como un derecho fundamental que en caso alguno se agota con el solo deber de fallar - pues ello sería cohe rente con un sistema cuyo eje es la sentencia que resuelve el conflicto-, sino que integra la

\footnotetext{
${ }^{111}$ NeRY (2004) p. 134.

112 Marinoni, (2007b) propuesta que permite un paso más allá, pues a partir del enfoque expuesto, vemos que el derecho de acción tendría un contenido doble, primero en cuanto asegura el acceso al proceso, pero al mismo tiempo, y en segundo lugar, incluye garantías dentro del proceso. Q ueda pendiente, e insinuado por el propio autor mencionado, por ejemplo, en M ARINONI (2006) p. 438, una tercera dimensión del derecho de acción, en cuanto debe garantizar una decisión "legítima" en cuanto a su contenido, o derechamente, justa.

113 MÜLLER (2004) p. 132.
} 
exigencia de tutela efectiva del derecho que se reclama, a la luz y de frente a los derechos fundamentales que le asisten tanto al actor, como al demandado.

Lo anterior no solo implica un resultado de adjudicación del derecho material correcto, sino que también incluye todos aquellos derechos de carácter procesal que integran cada etapa del procedimiento.

En este contexto, la inexcusabilidad integra algo mucho más amplio que el simple deber de fallar, sino que involucra su capacidad -y obligación- de respuesta en todas las etapas del ejercicio de jurisdicción, por lo que incluye y es evaluado no solo por el resultado de la adjudicación específica, sino que todos los actos procesales previos y posteriores a dicho evento.

En un trabajo conjunto de Oldpather, Bockhorst y Dimmer, se bosqueja la actividad y actitud jurisdiccional, partir de lo que denominan como "Judicial Responsiveness"114, que hemos preferido traducir - contextualizándolo a nuestro temacomo deber de respuesta judicial, que definen como el grado en que las decisiones judiciales son el producto de los argumentos y precedentes vinculantes puestos ante el tribunal por las partes en disputa115.

Proponen los autores, que el deber de respuesta de los tribunales se evalúa según la medida en que el judicial emite el producto de su adjudicación de manera coherente con lo aportado por las partes, en el contexto del "Judge as U mpire". Pero en lo que nos intere$\mathrm{sa}$, el argumento vertido por los autores mencionados, que hace referencia a la opinión de Lon Fuller respecto el ejercicio de la adjudicación, es que la legitimidad de la adjudicación no depende principalmente de si el juez es imparcial, conocedor del derecho, u otros atributos, sino de que el acto jurisdiccional sea el producto de un "marco institucional que tiende a asegurar a los litigantes una oportunidad para la presentación de pruebas y argumentos razonados"116, es decir, la legitimidad depende de las posibilidades de participación de las partes en un ambiente de "fair play"

De este modo, la inexcusabilidad ampliamente entendida, como correlato del derecho de acceso a la justicia, implica una obligación orgánica, esto es, destinada al juez, no solo de otorgar la oportunidad a los litigantes de acceder de manera significativa a un proceso judicial específico (ya sea demandando, ofreciendo prueba, argumentando, defendiéndose, etc.), sino de considerar - también de modo substancial-, dichos aportes en su rol jurisdiccional.

Plantea Lon Fuller, que la exigencia de congruencia referida, es inexcusable por parte del juez, pues cuando se ejerce jurisdicción sin considerar los aportes de las partes, "el proceso se vuelve falso, y para las partes, la participación en la decisión pierde todo sentido"117.

\footnotetext{
114 Oldfather et al. (2010).

115 Oldfather et al. (2010) p. 2, traducción libre de: "to defined as the extent to which judicial decisions are a product of the arguments and authorities put before court by the parties in di spute".

116 Oldfather et al. (2010) p. 4, traducción libre de: "institutional framework that is intended to assure to the disputant an opportunity for the presentation of proofs and reasoned argument".

117 Oldfather et al. (2010), citando a Fuller, Lon L., en The forms and limits of adjudication.
} 
En el mismo sentido se pronuncia WALDron, al señalar la importancia que debe tener en el proceso la rule of law, la que se debe concretar en cada uno de los procesos a través de los que se pueden denominar derechos procesales como el derecho a ser oído, el derecho a defensa, el derecho a estar presente en las instancias críticas del proceso, el derecho de la amplia defensa, y el derecho de apelación, fundado en un argumento kantiano, basado en el aspecto dignificador de la ley, que debe concretarse en los procesos judiciales, esto es, la consideración de que "todas las personas que viven bajo la ley, son portadores de razón e inteligencia"118, y por lo tanto una rule of law que se permita prescindir de dar la oportunidad a las partes de participar en el proceso de adjudicación, subestima dicha dignidad.

Favorable a la participación en el procedimiento, se muestra también Robert G. Bone ${ }^{119}$, quien utilizando la teoría de los derechos de Dworkin, propone el reconocimiento de la existencia de los derechos procesales, y su comprensión dentro de la teoría dworkiniana como efectivas cartas de triunfo, al igual que en el contexto político, de derechos humanos y derechos de fondo. Es interesante, que en este marco teórico, la exigencia de corrección no se limita solo a los aspectos procesales, sino también a la corrección del resultado mismo de la actividad judicial, destinada a hacer cumplir la ley substantiva.

\subsection{El PRINCIPIO DE INEXCUSABILIDAD COMO INAPARTABILIDAD}

Anteriormente ya nos referimos al hecho de que el principio de inexcusabilidad corresponde en estricto rigor, a un mandato dirigido específicamente al Poder Judicial, y que por lo tanto, no asegura de manera textual, que la ley no pueda sustraer de la competencia de los tribunales algún asunto o materia determinada ${ }^{120}$, como alguna vez sucedió en Brasil, lo que posteriomente fue solucionado con la Constitución Federal de 1988, mediante la consagración del principio constitucional de la "inafastabilidade", por la cual se prohíbe al legislador, apartar de la posibilidad de tutela judicial cualquier lesión 0 amenaza de lesión ${ }^{121}$.

Sin embargo, y sin perjuicio de lo anterior, entendido el derecho de acceso a la justicia, como lo define Álvaro de Oliveira, en cuanto: "poder de exigir del órgano judicial, en tiempo razonable, el desarrollo completo de sus actividades, tanto decisorias, con emisión de pronunciamiento procesal o de mérito sobre el objeto de la pretensión procesal, como que pueda ser realizado efectivamente del punto de vista material"122, nuestro principio de la inexcusabilidad, se estructura como fuente del deber correlativo del acceso a la justicia, y por lo tanto, comprende un deber o prohibición que tiene por fin asegurar y garantizar la plenitud del derecho de acción, en cuanto asegura el acceso a la tutela efectiva de los derechos.

\footnotetext{
118 WALDRON (2010) p. 17.

119 Bone (2010).

120 Carocca (1997) p. 36.

121 Inciso XXXV del artículo 5 de la Constitución Federal de Brasil de 1988 que señala: "a lei não excluirá da apreciação do Poder Judíciario lesão ou ameaça de lesão". Para una noticia histórica de este principio, ver NerY (2004) pp. 130 y ss.

122 Álvaro de Oliveira (2009) p. 192.
} 
En ese sentido, debería implicar una prohibición dirigida no solo al Estado Juez en cuanto concreta de manera orgánica el derecho de acción, sino también dirigido al Estado en general, pues al tratarse de un derecho fundamental, debe entenderse ínsito en él, que incluye un mandato de optimización y promoción del mismo.

De este modo, el legislador se encontraría limitado por este principio, y además, obligado a optimizarlo, pudiendo argumentar, que en estricto rigor, la inexcusabilidad así entendida, también prohíbe la "inapartabilidad"123 del control jurisdiccional de todo asunto, que cumpliendo los requisitos de la acción, se someta al conocimiento del órgano judicial.

Dicha construcción, complementaría también, la fundamentación del derecho de acción que nuestra Constitución consagra en el numeral $3^{\circ}$ del artículo 19, como elemento de la garantía del debido proceso, que como observa Aldunate, por regla general se despliega solo como una exigencia o deber para el legislador ${ }^{124}$, lo que a nuestro juicio, integrando el deber de inexcusabilidad, en una comprensión amplia, permite también exigirlo y configurarlo como un mandato de optimización y promoción contra el propio Poder Judicial, por lo que "la omisión del legislador no justifica la omisión del juez"125en la búsqueda de la concreta tutela de derechos, haciéndose exigible por tanto, el contenido de dicha garantía procesal, por medio del principio funcional.

\section{A MODO DE REFLEXIÓN}

"En un determinado momento el procesalista despertó y observó que la Justicia Civil era elitista - porque estaba apartada de la gran mayoría de la población, que por varias razones evitaba de recurrir al Poder Judicial- e inefectiva, ya que no cumplía aquello que prometía"126.

$\mathrm{N}$ os parece que la anterior cita, describe de buena manera las consecuencias en el derecho procesal del cambio de paradigma del Estado Constitucional, que hemos utilizado como eje central de estas líneas.

En dicho contexto, hemos querido proponer, que la inexcusabilidad debe entenderse como un pilar de la función jurisdiccional, y junto con la acción, como caras de una misma moneda, por cuanto correspondería a la obligación o deber estatal correlativo al derecho fundamental de tutela del derecho material reclamado judicialmente.

Sin embargo, como se ha expuesto, creemos que en el actual estado de la cuestión, no es suficiente entender como agotado este deber solo garantizando el derecho de acción como herramienta que pone en movimiento a la jurisdicción, sino que siendo menester tener en cuenta la tutela adecuada para la satisfacción plena y concreta del derecho que se

123 En este punto, hacemos expresa referencia al ya citado principio de "inafastabilidade", que es traducido por Juan José Monroy Palacios como principio de "inapartabilidad de la jurisdicción", ver nota al pie 23, en Alvaro de Oliveira (2008) p. 36.

124 Aldunate (2008) p. 200.

125 Marinoni (2007b).

${ }^{126}$ Marinoni (2008) p. 19. 
reclama127, parece metodológicamente acertado, reemplazar la expresión derecho de acción, por la de derecho de acceso a la justicia.

Los ideales del Estado Constitucional colocan la tutela jurisdiccional de los dere chos, como un derecho fundamental, objetivo de la labor jurisdiccional, que ya no puede sostenerse en la base de la mera resolución de conflictos.

Para conseguir una tutela efectiva e idónea del derecho que se reclama jurisdiccionalmente, se hace preciso entender el derecho procesal civil de una manera tópica, de cara al caso concreto, y así dilucidar, frente a la relación jurídica material, la tutela adecuada específica al derecho, siempre de cara a las necesidades en el plano material128, por lo que a fin de diferenciar esta visión, de la antigua manera de comprender el derecho de acción en el Estado Liberal, se ha preferido hablar de derecho de acceso a la justicia, pues dicho concepto involucra además, el compromiso del Estado, de no ser indiferente a las realidades sociales ${ }^{129}$, como ocurría en el paradigma anterior, y por lo tanto, de remover los obstáculos para el ejercicio del derecho de acción ${ }^{130}$, a fin de un real y concreto acceso a la justicia.

Asimismo, la inexcusabilidad, al sustentar de manera orgánica y funcional el dere cho de acceso a la justicia, debe incluir la posibilidad de la construcción tópica de la tutela efectiva a cada derecho concretamente exigido, sin distinguir si se trata de derechos procesales 0 substanciales puros, o procesales con efectos substanciales'131, pues la acción procesal o derecho de acceso a la justicia, debe entenderse como un bloque que incluye todas las exigencias procesales y de fondo que estructuran las etapas previas a la acción judicial, y las propiamente judiciales, de conocimiento, de mérito, y por supuesto, de ejecución, frente al mandato de la tutela efectiva.

Esta obligación de dar tutela efectiva, nos remite a una tutela "justa", correcta en re lación con el derecho objetivo cuya protección se reclama, lo que impone al Estado - tanto al juez como al legislador-, la obligación viabilizar el acceso a la justicia, atenuando las diferencias que produce el costo del proceso (incluyendo las tasas o pago de multas como condición del derecho de recurrir o apelar), y otorgando asistencia gratuita para los desprovistos de recursos.

Asimismo, obliga a considerar la demora en la tramitación de los procesos, como un obstáculo para quien no tiene condiciones financieras de soportar una espera prolongada de resolución, o derechamente constituye una denegación de la justicia, atendida la naturaleza del derecho que se reclama.

Lo interesante, y como asunto cuyo estudio queda pendiente, es que el acceso a la justicia implica además, una visión instrumental del proceso, en cuanto herramienta 0 técnica que permite alcanzar el fin del ejercicio del control jurisdiccional, que es la tutela efectiva de los derechos, por lo que el proceso utilizado para ello, debe además de ser idóneo, debe ser justo y legítimo, pues como señala Álvaro de O liveira "En el caso del

127 MÜlLeR (2004) p. 139.

128 MÜlLER (2004) p. 140.

${ }^{129}$ Marinoni (2006) p. 184.

130 Marinoni (2007b).

131 Solum (2005). 
proceso, el fin es el ideal de justicia material del caso concreto", donde el proceso justo y la comprensión de tutela jurisdiccional efectiva son "los medios de que dispone el Estado democrático de derecho (...) para la realización de tal fin"132, lo que exige un deber del órgano judicial que va más allá de la simple respuesta al requerimiento, pues se pretende y demanda una decisión justa en un contexto instrumental procesal también justo, único camino que eleva "las posibilidades de un resultado justo"133.

\section{CONCLUSIONES}

1. Confrontadas las noticias históricas en que se suele fundar el origen del principio de inexcusabilidad, nos parece forzoso concluir que el antecedente directo que sirve de fuente a nuestro principio, corresponde al concepto francés positivado en el artículo $4^{\circ}$ del Code Civil, que por cierto responde al paradigma ilustrado republicano, que hemos denominado como Estado Legislativo, introducido en Chile en la República.

2. Q ue atento a lo anterior, nos parece que la delimitación correcta del principio de la inexcusabilidad dice estricta relación con los valores que se intentaban proteger con su intermedio, principalmente, el deber de fallar ineludible frente al requerimiento que reúne los requisitos, y por lo tanto se configuró como un principio transversal de la jurisdicción, que fluyó tempranamente desde el año 1875, ahora implementado a partir del artículo 76 (antiguo 73) de la CPR, desplegándose en otras normas, como el artículo 24 del CC, 170 $N^{\circ} 5$ del CPC, y 112 del propio COT.

3. Que la comprensión original del principio de inexcusabilidad, se reconducía plenamente al deber de fallar que presidía la estructura política de los ideales del Estado Legislativo, la creciente y progresiva influencia de visiones normativistas, redujeron la comprensión del principio a una regla de excepción que autoriza la integración por parte del juez, de la denominada jurisdicción de equidad.

4. Q ue frente a los cambios impulsados por el tránsito del paradigma del Estado Legislativo al Estado Constitucional, y especialmente enfrentados a una comprensión del derecho dúctil formado de principios y reglas, las teorías de la argumentación y principalmente el hecho del mundo, que corresponde a la cultura de los derechos humanos, que permite distinguir entre un derecho explícito y otro implícito, revelable a la luz de los contenidos constitucionales, el principio de inexcusabilidad, en su comprensión más restringida, ha perdido relevancia, ya que la referida ductilidad del derecho, no hace necesario recurrir a fuentes externas para construir norma decisoria litis, pues todo problema de supuesta laguna o imperfección legal, es reconducible a una interpretación constitucional, que dota de sentido las carencias normativas, o derechamente, permite extraer principios del propio sistema, que se despliegan como normas de fondo.

5. Postulamos, entonces, una nueva comprensión del principio de inexcusabilidad, unido al concepto de derecho de acción, y este reformulado de la manera coherente con el

\footnotetext{
132 Álvaro de Oliveira (2009) p. 197.

133 Del Claro (2009) p. 104: "Q uando o juiz respei ta e faz respeitar os di rei tos processuais ele maximiza as chances de um resultado justo".
} 
Estado Constitucional, esto es, como derecho de acceso a la justicia y tutela efectiva de los derechos.

6. En dicho sentido, proponemos desplegar el principio de inexcusabilidad como la contracara o correlato orgánico-funcional del derecho de acción procesal, en cuanto principio, mandato de optimización, y fuente del derecho fundamental de acceso a la justicia.

7. Q ue lo anterior, sin perjuicio de considerar que falta una complementación expresa de este principio, que consagre por un lado, una cláusula de inapartabilidad, que impida al legislador sustraer del conocimiento del judicial, todo asunto, y por otro, que se permita expresamente una apertura de aplicación de la inexcusabilidad a la creación tópica de procedimientos, que con pleno respeto a los principios del Estado Constitucional, permita escapar del concepto de jurisdicción basado en el conflicto y la sentencia, y centrado en la tutela efectiva de los derechos, permita al juez, optimizar en cada estado procesal, y extraprocesal (instancias prejudiciales), la protección concreta de los derechos, mediante la tutela de mérito, la anticipación de la tutela, etc.

\section{BIBLIOGRAFÍA}

1. Actas de la "Comisión Ortúzar", disponible en www.ben.cl

2. Aldunate Lizana, Eduardo (2008): D erechos Fundamentales (Santiago, Editorial Legal Publishing) 439 pp.

3. Aldunate Lizana, Eduardo (2009): Constitución política de la República de Chile, doctrina y jurisprudencia (Punto Lex, Santiago) 1374 pp.

4. Alexy, Robert (2008): Teoría de los derechos fundamentales (Traducc. Carlos Bernal Pulido, M adrid, Centro de Estudios Políticos y Constitucionales) 600 pp.

5. Álvaro de Oliveira, Carlos Alberto (2008): Teoría y práctica de la tutela jurisdiccional (Traducc. Juan José Monroy Palacios, Lima, Communitas) 336 pp.

6. Álvaro de Oliveira, Carlos Alberto (2009): "El derecho a la tutela jurisdiccional efectiva desde la perspectiva de los derechos fundamentales", Revista de Derecho (Valdivia), vol XXI, n 1: pp. 185-201.

7. Ansaldi, O ctavio, Chandía, Sebastián, Flores, Walda, y Pardo, M aría Soledad (2008): La (in)comprensión del principio de inexcusabilidad en sede constitucional, disponible en বttp://congresoconstitucional.cl/wp-content/uploads/2010/08/ansaldiet-al_1254938264.pdf>, [fecha de consulta: 25 de marzo de 2011]

8. Atienza, M anuel, Ruiz Manero, Juan (1991): Sobre principios y reglas, Revista D oxa, Cuadernos de Filosofía del Derecho, 10: pp. 101-120.

9. Atienza, Manuel y Ferrajoli, Luigi (2005): Jurisdicción y Argumentación en el Estado Constitucional de Derecho (Universidad Nacional Autónoma de M éxico, M éxico, 2005), 133 pp.

10. Atienza, M anuel (2007): “Argumentación y Constitución” en Aguiló Regla, Josep; Atienza, M anuel y Ruiz Manero, Juan, Fragmentos para una Teoría de la Consti tución (M adrid, lustel) 190 pp. 
Martínez Benavides, Patricio “ “El principio de inexcusabilidad y el derecho de acción..."

11. Ballesteros Ríos, Manuel (1890): La lei de organización i atribuciones de los tribunales de Chile; antecedentes, concordancias i aplicación práctica de sus disposiciones (Santiago, Editorial $\mathrm{N}$ acional).

12. Bermúdez Soto, Jorge (2010): "Estado actual del control de legalidad de los actos administrativos. ¿Q ué queda de la nulidad de derecho público?", Revista de Derecho (Valdivia), vol XXIII, n 1, pp. 103-123.

13. Bone, Robert G. (2010): "Procedure, participation, rights", en Boston U niversity Law Review, vol 90, pp. 1011-1028.

14. Bravo Lira, Bernardino (2009): "Judicatura e institucionalidad en Chile", en: El mismo, El juez entre el derecho y la ley, en el mundo hispánico. Del estado de derecho al derecho del estado (siglos XVI a XXI) (Santiago, Editorial LegalPublishing) pp. 165-199.

15. Bulygin, Eugenio (2003): "Los jueces ¿crean derecho?", en: (comp.) Malem, Jorge, O rozco, Jesús y VÁsquez, Rodolfo, La función judicial, ética y democracia (Barcelona, Editorial Gedisa) p. 21-37.

16. Calamandrei, Piero (1960): Proceso y democracia (Buenos Aires, Editorial Rejea) 237 $\mathrm{pp}$.

17. Carocca Pérez, Alex (1997): Derechos humanos y derecho civil: perspectiva procesal (Santiago, C entro de D esarrollo Jurídico Judicial) $101 \mathrm{pp}$.

18. Casarino Viterbo, Mario (1995): M anual de derecho procesal. Derecho procesal orgánico, I (Santiago, Editorial Jurídica de Chile) 328 pp.

19. Chiovenda, Giusseppe (2001): Instituciones de derecho procesal civil 3 (Traducc. E. Gómez Orbaneja, M éxico, Editorial Jurídica U niversitaria) 672 pp.

20. Соцомво Cамpbell, Juan (1991): La jurisdicción en el derecho chileno, un aporte al estudio del conflicto y sus formas de solución (Santiago, Editorial Jurídica) 64 pp.

21. Couture, Eduardo J. (2001): Estudios, ensayos y lecciones de derecho procesal civil, v. 2 (M éxico, Editorial Jurídica Universitaria) 475 pp.

22. De la Oliva Santos, Andrés, Díez-Picazo Gimenez, Ignacio, y Vega Torres, Jaime (2008) Derecho procesal. Introducción (Madrid, Editorial Universitaria Ramón Areces) $454 \mathrm{pp}$.

23. Del Claro, Roberto (2009), Direcao material do processo, Tesis D octoral, Facultad de D erecho de la U niversidad de São Paulo, $271 \mathrm{pp}$.

24. Dworkin, Ronald (1989): Los derechos en serio (Traducc. Marta Guastavino, Barcelona, Editorial Ariel D erecho) $508 \mathrm{pp}$.

25. Dworkin, Ronald (2005): El imperio de la justicia (Traducc. Claudia Ferrari, Barcelona, Editorial Gedisa) 328 pp.

26. Echeverrí́, Rafael (1997): El Búho de M inerva (Santiago, D olmen) 315 pp.

27. Endicott, Timothy A. O . (2006): La vaguedad en el derecho (Traducc. J. Alberto del Real Alcalá y otro, M adrid, Editorial D ykinson) p. 303.

28. Eyzaguirre Gutiérrez, Jaime (2003): Historia del derecho (Santiago, Editorial Universitaria) $226 \mathrm{pp}$.

29. Ezquiaga Ganuzas, Francisco Javier (2003): "Función legislativa y función judicial: la sujeción del juez a la ley", en: (comp.) Malem, Jorge, O rozco, Jesús y VÁsquez, Rodolfo, La función judicial, ética y democracia (Barcelona, Editorial G edisa) 39-55. 
30. Figueroa Quinteros, M aría Angélica (1996): Algunos antecedentes históricos sobre los principios de inexcusabilidad y legalidad, en Revista de Estudios H istórico-Jurídicos, V. XVIII, pp. 187-196

31. González Pérez, Jesús (1984): El derecho a la tutela jurisdiccional (M adrid, Editorial Civitas) $160 \mathrm{pp}$.

32. Guastini, Riccardo (2001), Estudios de teoría constitucional (Traducc. M iguel Carbonell y otros, M éxico, U N AM ) 278 pp.

33. Guzmán Brito, Alejandro (2007): Las reglas del "código civil" de Chile sobre interpretación de las leyes (Santiago, Editorial LexisN exis) 258 pp.

34. Hoyos Henrechson, Francisco (1978), "La jurisdicción", en Revista de Derecho Procesal , 12, p. 77-134.

35. Husson, Leon (1980): “Un débat révélateur: la discusión de lárticle 4 du code napoleón", en: (coord.) Rodríguez García, Fausto, Estudios en H onor del Doctor Luis Recaséns Siches (M éxico, U N AM ) pp. 525-540.

36. LAporta, Francisco (2002): "La creación judicial y el concepto de derecho implícito", en Revista jurídica de la U niversidad Autónoma de M adrid, v. 6, p. 135-151.

37. Lopera Mesa, Gloria Patricia (2004): "Los derechos fundamentales como mandatos de optimización", en Revista D oxa, Cuadernos de Filosofía del D erecho, 27, pp. 211-243.

38. LyotaRd, Jean François (1999): La Posmodernidad (explicada a los niños), (Barcelona, Editorial Gedisa) $122 \mathrm{pp}$.

39. Marinoni, Luiz Guilherme (2004): Técnica processual e tutela dos direitos (São Paulo, Editora Revista dos Tribunais) $700 \mathrm{pp}$.

40. Marinoni, Luiz Guilherme (2005): "A jurisdicao no estado contemporáneo" (coord. por él mismo) en Estudos de D ireito Processual Civil. H omenagem ao Profesor Egas D irceu M oniz de Aragao (São Paulo, Editora Revista dos Tribunais) pp. 13-66.

41. Marinoni, Luiz Guilherme (2006): Curso de Processo Civil v. 1, teoría geral do processo (São Paulo, Editora Revista dos Tribunais) 511 pp.

42. Marinoni, Luiz Guilherme (2007a): D erecho Fundamental a la tutela jurisdiccional efectiva. Del proceso civil clásico a la noción de derecho a la tutela jurisdiccional efectiva (Traducc. Aldo Zela Villegas, Lima, Palestra Editores) 340 pp.

43. Marinoni, Luiz Guilherme (2007b), "El derecho de acción en la constitución brasileña", en Revista lus et Praxis v. 13 (2) pp 57 - 80.

44. Marinoni, Luiz Guilherme (2008): Anticipacao da tutela (São Paulo, Editora Revista dosTribunais) $317 \mathrm{pp}$.

45. Marinoni, Luiz Guilherme (2009): "Aproximacao crítica entre as jurisdicoes de civil law e de common law", en Revista da Faculdade de Direito Universidade Federal do Paraná, v. 49, , pp. 1-58

46. Marinoni, Luiz Guilherme (2010): Os precedentes na dimensao da seguranca juridica, disponible en www.marinoni.adv.br, [última revisión, 1 de abril de 2010].

47. Marinoni, Luiz Guilherme y Cruz Arenhart, Sergio (2007): Curso de Processo Civil v. 2, processo de conhecimento (São Paulo, Editora Revista dos Tribunais), 814 pp. 
Martínez Benavides, Patricio - “El principio de inexcusabilidad y el derecho de acción...

48. Marinoni, Luiz Guilherme, Pérez Ragone, Álvaro y Núñez Ojeda, Raúl (2010): Fundamentos del proceso civil. Hacia una teoría de la adjudicación (Santiago, Abeledo Perrot) $484 \mathrm{pp}$.

49. Montesquieu (i973): D o espiritu dasleis (São Paulo, Abril Cultural), p. 158.

50. Montoro Ballesteros, Alberto (1980): Conflicto social, derecho y proceso (M urcia, Secretariado de publicaciones U niversidad de M urcia) 104 pp.

51. Müller, Julio Guilherme (2004): Direitos fundamentais processuais, Tesis requisito parcial para la obtención del grado de M agíster en D erecho en la U niversidad Federal do Paraná (Curitiba) 251 pp.

52. Nery Junior, Nelson (2004): Princípios do processo civil na constituição federal (São Paulo, Editora Revista dos Tribunais) 299 pp.

53. Núñez OjedA, Raúl (2008): “El sistema de recursos procesales en el ámbito civil en un estado democrático deliberativo", en Revista Ius et Praxis, año 14, n 1, pp. 199223.

54. Oldfather, Chad M., Bockhorst, Joseph P., Dimmer, Brian P. (2010): “Judicial inaction in action? Toward a measure of judicial responsiveness", en M arquette U niversity Law School Legal Studies Research Paper Series, 10-32, pp. 1-29

55. Orellana Torres, Fernando (2006): Manual de derecho procesal, 2 (Santiago, Editorial Librotecnia) 503 pp.

56. Pérez Ragone, Álvaro (2006a): “D eber de transparencia patrimonial y efectividad de la ejecución: corolario del imperativo de cooperación procesal", en varios autores La reforma procesal civil en Chile (Santiago, Cuadernos de Extensión Jurídica, U niversidad delos Andes) pp. 226-234.

57. Pérez Ragone, Álvaro (2006b): “El acceso a la tutela ejecutiva del crédito: reflexiones sobre la ejecución inmediata de sentencia, el proceso monitorio y los tribunales de ejecución desde el proceso civil comparado europeo" (ed.) Silva Prado, José Pedro, García García, José Francisco y Leturia Infante, Francisco en Justicia Civil y Comercial: Una reforma pendiente. Bases para el diseño de la reforma procesal civil. (Santiago, Fundación Libertad y D esarrollo) pp. 493 - 519

58. Portalis, Jean-Etienne (1959): Discurso preliminar sobre el proyecto de código civil presentado el primero de pluvioso del año IX por la comisión designada por el gobierno consular (Traducc. Carlos Suárez Anzorena, Buenos Aires, Abeledo Perrot) 60 pp.

59. Rabossi, Eduardo (1990): "La teoría de los derechos humanos naturalizada", en Revista del Centro de Estudios Constitucionales, 5, enero - marzo.

60. Romero Seguel, Alejandro (2006): Curso de derecho procesal civil. La acción y la protección de los derechos, I (Santiago, Editorial Jurídica) 124 pp.

61. Rorty, Richard (2000): Verdad y progreso. Escritos filosóficos 3 (Traducc. Ángel García Bermejo, Barcelona, Paidos Básica) 399 pp.

62. Silva Bascuñán, Alejandro (2010): Tratado de derecho constitucional, I, versión disponible en www.microjuris.cl, [última revisión, 29 de marzo de 2011].

63. Solum, Lawrence B. (2005): "Procedural Justice", en Legal Studies Research Paper Series, 06-14 (San D iego, University of San D iego, School of Law) pp 181-321. 
64. Tarello, Giovanni (1987): Storia della cultura giuridica moderna (Bologna, II M ulino) $635 \mathrm{pp}$.

65. Taruffo, M ichele (2005), “La motivazione della sentenza”, en: (coord.) Marinoni, Luiz G uilherme, Estudos de D irei to Processual Civil. H omenagem ao Profesor Egas D irceu M oniz de Aragao (São Paulo, Editora Revista dos Tribunais) pp. 166-174.

66. TAruffo, M ichele (2008a): La prueba de los hechos (Traducc. Jordi Ferrer Beltrán, M adrid, Editorial Trotta) 542 pp.

67. Taruffo, M ichele (2008b): La prueba (Traducc. Laura Manríquez y Jordi Ferrer Beltrán, Barcelona, Editorial M arcial Pons) 324 pp.

68. Tejada Gorráiz, Q ueralt (1999): "La crisis de la Ley", en Cuadernos electrónicos de Filosofía del D erecho, 2, disponible en http://www.uv.es/CEFD/2/queralt.html

69. Topasio Ferreti, Aldo (1983): "Fundamentos históricos del principio de inexcusabilidad del juez en el devenir jurídico hispánico y chileno", en Revista Chilena de H istoria del Derecho, $n^{\circ}$ 9, pp 155-164.

70. Verdugo Marinkovic, Mario, Pfeffer Urquiaga, Emilio y Nogueira Alcalá, H umberto (1994): D erecho constitucional II, tomo II (Santiago, Editorial Jurídica).

71. Vienweg, Theodor (1964): Tópica y Jurisprudencia (Trad. Luis D íez-Picazo, M adrid, Editorial Taurus) 143 pp.

72. WaLdron, Jeremy (2010): "The rule of law and the importance of procedure", en Public Law \& Legal Theory Research Paper Series, N ew York University, School of Law, working paper $\mathrm{N}^{\circ} 10-73$, pp. 1-25.

73. Welsch, Wolfgang, "Topoi de la Posmodernidad" (1997): en Fischer, Retzer, A, y Schweizer J., El Final de los Grandes Proyectos (traducc. Javier Legáis, Barcelona, Editorial Gedisa) pp. 36-56.

74. Zagrebelsky, Gustavo (2003): El derecho dúctil (Traducc. M arina Gascón, M adrid, Editorial Trotta), 156 pp.

\section{NORMAS CITADAS}

- Constitución Política de la República (CPR)

- Código Civil (CC)

- Código de Procedimiento Civil (CPC)

- Código O rgánico de Tribunales (COT) 
